\title{
ASIC DESIGN OF RF ENERGY HARVESTER USING 0.13UM CMOS TECHNOLOGY
}

\author{
A Thesis \\ presented to \\ the Faculty of California Polytechnic State University,
}

San Luis Obispo

In Partial Fulfillment

of the Requirements for the Degree

Master of Science in Electrical Engineering

by

Jainish Zaveri

August 2018 
(C) 2018

Jainish Kiran Zaveri

ALL RIGHTS RESERVED 
TITLE: $\quad$ ASIC Design of RF Energy Harvester using 0.13um CMOS Technology

\author{
AUTHOR: Jainish Zaveri \\ DATE SUBMITTED: August 2018
}

COMMITTEE CHAIR: Dr. Tina Smilkstein, Ph. D

Professor of Electrical Engineering

COMMITTEE MEMBER: Dr. Andrew Danowitz, Ph. D

Professor of Electrical Engineering

COMMITTEE MEMBER: Dr. Dennis Derickson, Ph. D

Professor of Electrical Engineering 


\section{ABSTRACT \\ ASIC Design of RF Energy Harvester using 0.13um CMOS Technology \\ Jainish Zaveri}

Recent advances in wireless sensor nodes, data acquisition devices, wearable and implantable medical devices ${ }^{[1]\left[{ }^{[2]}[3]\right.}$ have paved way for low power (sub 50uW) devices. These devices generally use small solid-state or thin film batteries for power supply which need replacement or need to be removed for charging. RF energy harvesting technology can be used to charge these batteries without the need to remove the battery from the device, thus providing a sustainable power supply. In other cases, a battery can become unnecessary altogether. This enables us to deploy wireless network nodes in places where regular physical access to the nodes is difficult or cumbersome.

This thesis proposes a design of an RF energy harvesting device able to charge commercially available thin film or solid-state batteries. The energy harvesting amplifier circuit is designed in Global Foundry 0.13um CMOS technology using Cadence integrated circuit design tools. This Application Specific Integrated Circuit (ASIC) is intended to have as small a footprint as possible so that it can be easily integrated with the above-mentioned devices. While a dedicated RF power source is a direct solution to provide sustainable power to the harvesting circuit, harvesting ambient RF power from TV and UHF cellular frequencies increases the possibilities of where the harvesting device can be placed. The biggest challenge for RF energy harvesting technology is the availability of adequate amount of RF power. This thesis also presents a survey of available RF power at various ultra-high frequencies in San Luis Obispo, CA. The idea is to determine the frequency band which can provide maximum RF power for harvesting and design a harvester for that frequency band. 


\section{TABLE OF CONTENTS}

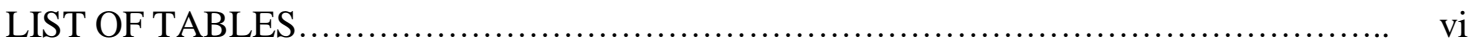

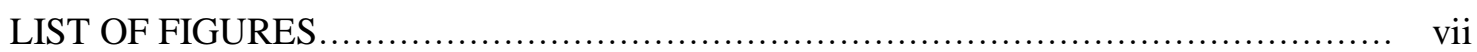

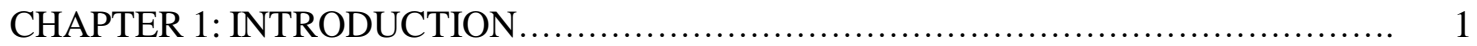

CHAPTER 2: LITERATURE SURVEY ..................................................... 4

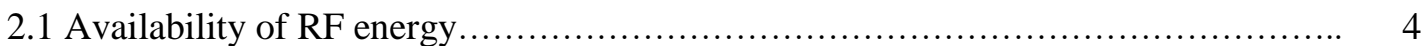

2.1.1 Study of ambient RF power survey ............................................. 5

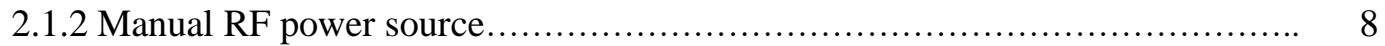

2.2 Block diagram of RF energy harvester................................................. 8

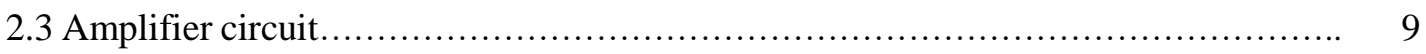

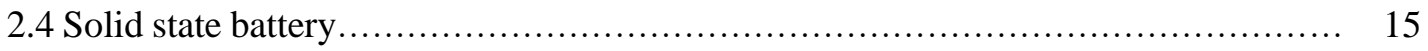

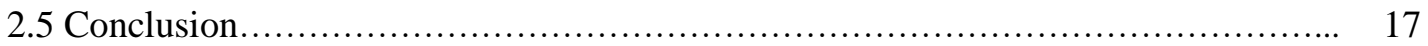

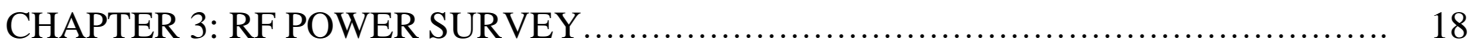

3.1 Study of cellular communication frequency bands..................................... 18

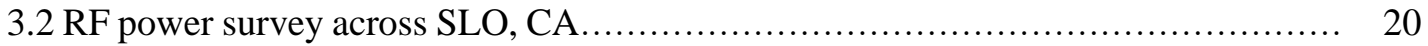

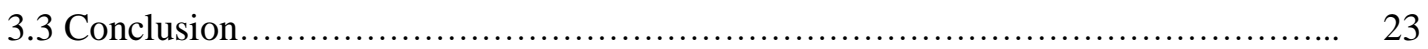

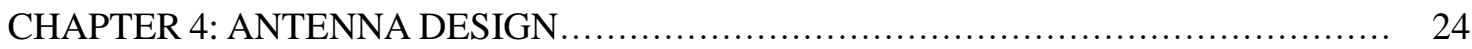

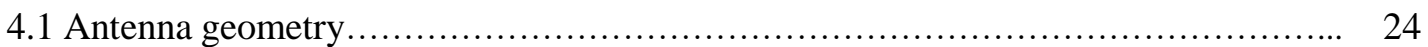

4.2 Antenna parameters calculation....................................................... 25

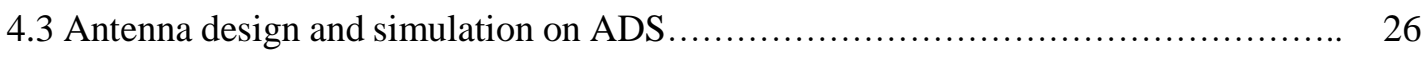

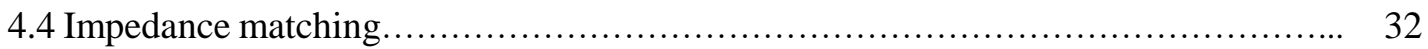

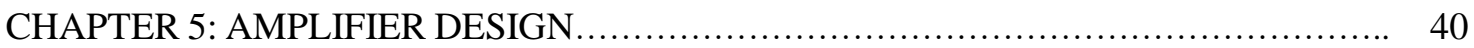

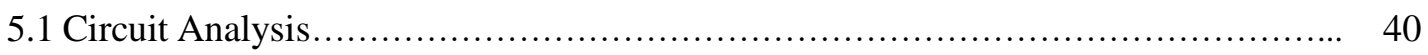

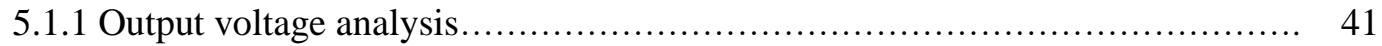

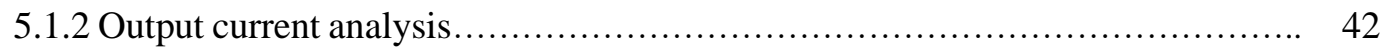

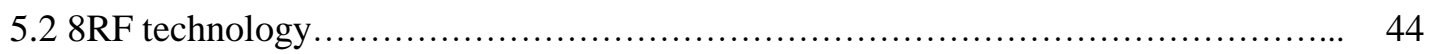

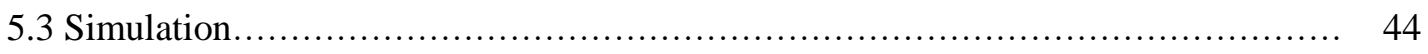

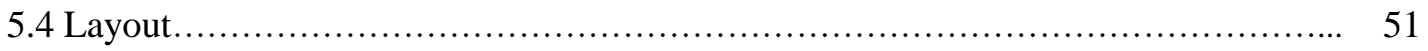

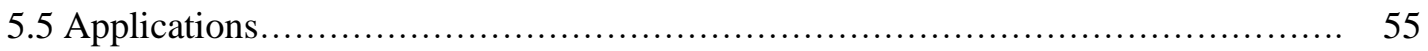

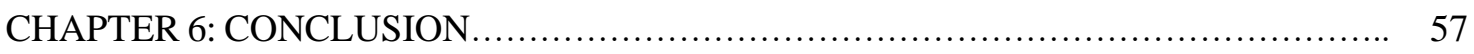

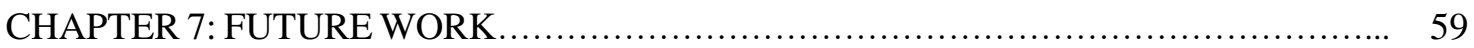

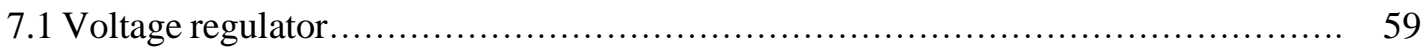

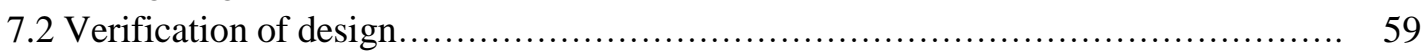

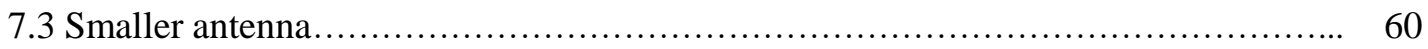

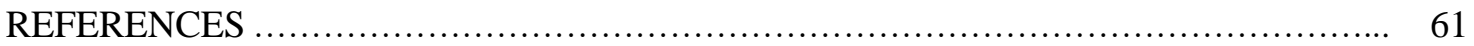




\section{LIST OF TABLES}

Table 2. 1: Summary of RF power observed in Guangdong, China [8] .................................... 6

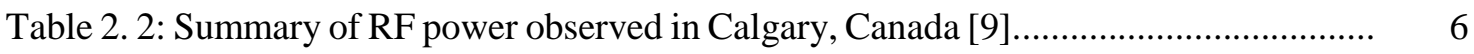

Table 2. 3: Summary of RF power observed in Nanyang Polytechnic, Singapore [10]......... 7

Table 2. 4: Power in $\mathrm{dBm}$ and Watts............................................... 7

Table 2. 5: Technical specifications of CBC005 solid state battery [29] ................. 16

Table 3. 1: List of cellular frequency bands and their corresponding owners [18] .......... 19

Table 3. 2: Peak RF power averaged over a period of 10 days across each location............... 21

Table 4. 1: Calculated dimensions of both the antennas to be designed................................ 26

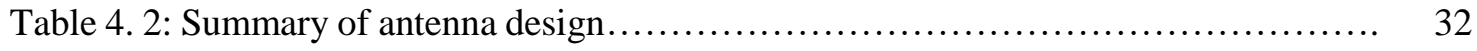

Table 4. 3: Calculated values of impedance matching components...................... 36

Table 5. 1: Input power vs input voltage relationship............................. 45

Table 5. 2: Summary of various simulation results............................... 50

Table 5. 3: Input-Output results from the simulations of amplifier...................... 51

Table 5. 4: Output voltages resulting from given input voltage levels................... 51

Table 5. 5: Potential applications that can be integrated with RF energy harvesting device... 56

Table 6. 1: Summary of the designed RF energy harvesting device..................... 58 


\section{LIST OF FIGURES}

Figure 2. 1: Block diagram of RF energy harvesting device............................. 8

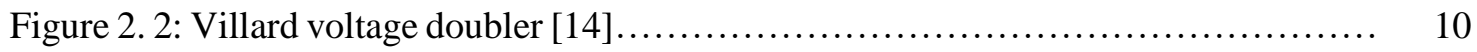

Figure 2. 3: (a)Villard topology (b)Dickson topology [15]......................... 11

Figure 2. 4: (a)PMOS floating gate transistor (b) Amplifier using PMOS floating gate

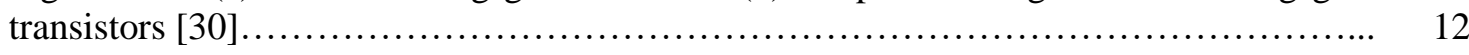

Figure 2. 5: Output voltage vs number of rectifier stages and transistor width [30]........ 13

Figure 2. 6: Voltage doubler using gate tied MOSFETs as diodes [16].................. 14

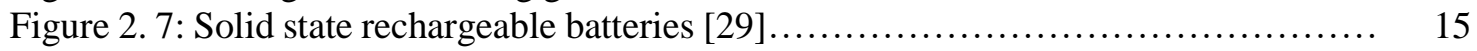

Figure 2. 8: Charging profile of Enerchip CBC005[29].......................... 16

Figure 2. 9: Charging profile of Enerchip CBC050[29]........................... 16

Figure 3. 1: Distribution of 734 districts for frequency regulation across USA [17]....... 18

Figure 3. 2: Map showing various locations of cellular transmission towers [19].......... 20

Figure 3. 3: (a) Highland drive (b) Start of P trail (c) Opposite California Highway Patrol

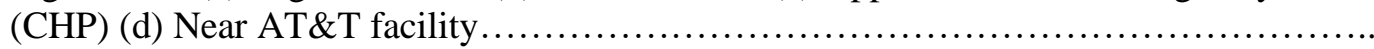

Figure 3. 4: (a) Peak RF power measured across San Luis Obispo over 10 days for frequencies between $820-920 \mathrm{MHz}$ (b) Peak RF power measured across San Luis Obispo

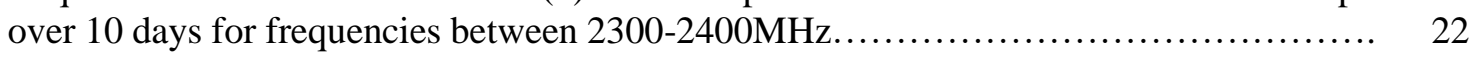

Figure 4. 1: (a) Top view of the patch (b) Side view of the patch [7] ................... 24

Figure 4. 2: 2.4GHz patch antenna (a) layout of antenna (b)schematic of antenna........... 27

Figure 4. 3: $915 \mathrm{MHz}$ patch antenna (a) layout of antenna (b)schematic of antenna........ 27

Figure 4. 4: Magnitude and Phase plots for $2.4 \mathrm{GHz}$ antenna......................... 28

Figure 4. 5: Magnitude and Phase plots for $915 \mathrm{MHz}$ antenna......................... 28

Figure 4. 6: 3D view of far field radiation pattern for $2.4 \mathrm{GHz}$ antenna.................. 29

Figure 4. 7: 3D view of far field radiation pattern for $915 \mathrm{MHz}$ antenna.................. 29

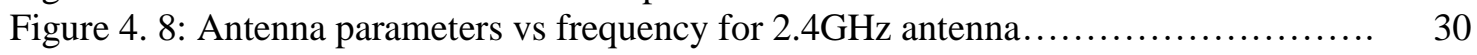

Figure 4. 9: Antenna parameters vs frequency for $915 \mathrm{MHz}$ antenna.................... 31

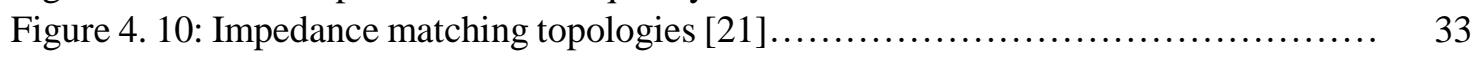

Figure 4. 11: Series Capacitance, parallel inductance matching circuit [21]....................... 34

Figure 4. 12: Circuit to determine channel resistance of diode connected NMOS......... 35

Figure 4. 13: Model of matching network along with the source resistance and input

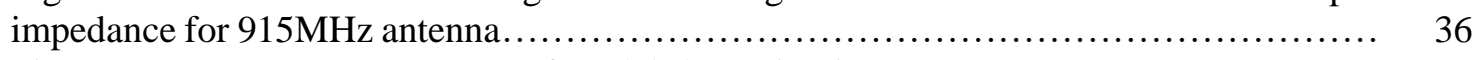

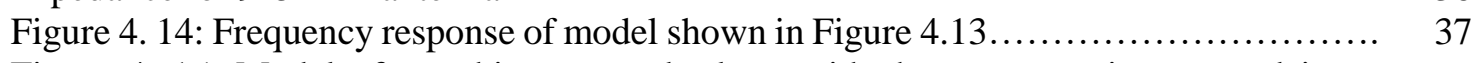

Figure 4. 15: Model of matching network along with the source resistance and input

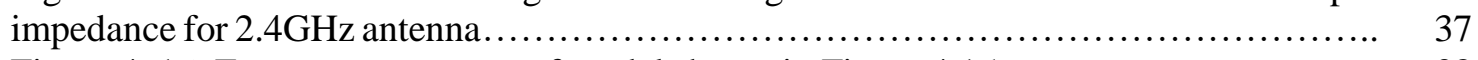

Figure 4. 16: Frequency response of model shown in Figure $4.15 \ldots \ldots \ldots \ldots \ldots \ldots \ldots \ldots \ldots \ldots$

Figure 5. 1: Single stage voltage doubler..................................... 40

Figure 5. 2: Transient response of single stage voltage doubler....................... 46

Figure 5. 3: Two stage voltage doubler......................................... 47

Figure 5. 4: Transient response of two stage voltage doubler....................... 47

Figure 5. 5: Four stage voltage doubler....................................... 48

Figure 5. 6: Transient response of four stage voltage doubler.......................... 48

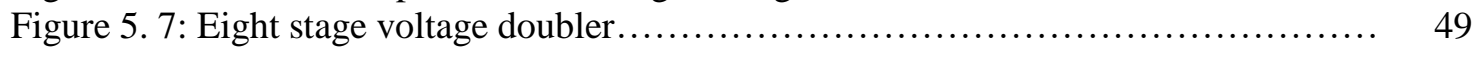

Figure 5. 8: Transient response of eight stage voltage doubler...................... 49

Figure 5. 9: Transient response of final design................................. 50

Figure 5. 10: (a) 3D view of NMOS structure (b) Structure of MIM and MIS capacitor

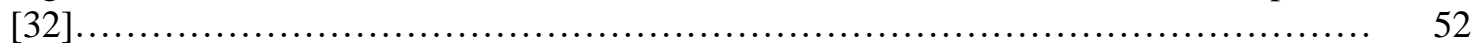


Figure 5. 11: Layout of single stage of amplifier............................... 53

Figure 5. 12: Layout of the final eight stage amplifier............................ 53

Figure 5. 13: Final optimized layout....................................... 54

Figure 7. 1: (a) Molex multi band ceramic chip antenna [36] (b) Abracon 915MHz ceramic

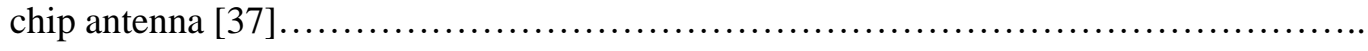




\section{CHAPTER 1 \\ INTRODUCTION}

In the past few years, the field of low power wireless devices is rapidly increasing in number. With the advent of IoT (Internet of Things) devices the number of wireless devices has increased sharply. It is estimated that by 2020 the number of IoT devices in the world would exceed 50 billion ${ }^{[4]}$. Wireless sensor networks, implantable and wearable medical devices, low power data acquisition devices are a few examples of IoT devices that consume very low power. Recent advances in these device technologies have introduced devices which consume power in the range of micro-watts ${ }^{[1][2][3][5]}$.

RF (Radio Frequency) energy harvesting shows a lot of potential to provide energy to these low power devices. It promises a power supply without the need to remove the battery from the device for charging or replacement. The RF energy required for harvesting can be provided manually or can be scavenged from existing RF sources in our surroundings. Scavenging energy from existing RF sources provides us an inexpensive way to power our devices without the need to set up additional infrastructure to facilitate our technology.

The radio spectrum is divided into various bands by the governing body FCC (Federal Communications Commission) ${ }^{[6]}$. Each of these bands serve a specific purpose like Satellite communication, AM/FM broadcasting, TV broadcasting, cellular communication, etc. Some of these frequency bands like the TV broadcasting and cellular communication bands carry adequate amount of energy to satisfy our energy harvesting 
goals of a few micro-watts. These bands are typically in the Ultra High Frequency (UHF) domain, i.e. from $300 \mathrm{MHz}-3 \mathrm{GHz}{ }^{[6]}$.

While the number of IoT devices are increasing, the size of these devices is decreasing. Thus, it is important to provide an energy harvesting solution that not only matches the power requirement but is also small in size. The answer to designing a small energy harvesting device lies in CMOS technology and Application Specific Integrated Circuit (ASIC) design. CMOS technology offers transistor sizes as low as a few nanometers and thus allows for an ASIC with a small footprint. This thesis presents the design of a RF energy harvesting device aimed at powering some low power devices. The device consists of an antenna, a matching circuit and the CMOS Amplifier IC. The design uses Global Foundry's 130nm 8RF CMOS technology for IC design and Keysight's Advanced Design Systems for Antenna Design.

The contents of this thesis can be summarized as follows. Chapter 2 provides literature survey of the technology. It discusses results of past surveys of ambient RF energy and various design methods involved in designing the rectifier amplifier circuit. Chapter 3 provides a survey of ambient RF energy available for harvesting in San Luis Obispo, CA. It discusses the survey methodology, results and draws conclusion on which frequency bands need to be used for energy harvesting. Chapter 4 is aimed at antenna design and the impedance matching network design. It gives details about important antenna characteristics like radiation pattern, gain, efficiency, etc. as a function of frequency. Chapter 5 presents the design of the rectifying and amplifying circuit. It 
discusses various parameters that affect the output voltage and harvested power. It also presents the layout of the final chip. Chapter 6 presents the conclusion of the thesis. Chapter 7 discusses the future scope of this thesis. It presents various ways to improve the existing design or complement the design with other technologies to improve the performance achieved in this thesis. 


\section{CHAPTER 2}

\section{LITERATURE SURVEY}

\subsection{Availability of RF energy}

The study of ambient RF energy harvesting begins with determining the available RF power in various frequency bands. The spatial distribution of RF energy sources determines the available RF power at a given location. This can be seen from the Friis transmission equation ${ }^{[7]}$.

$$
P_{r}=\frac{P_{t} G_{t} G_{r} \lambda^{2}}{(4 \pi R)^{2}}
$$

$\mathrm{P}_{\mathrm{r}}-$ received power

$\mathrm{P}_{\mathrm{t}}-$ transmitted power

$\mathrm{G}_{\mathrm{r}}-$ gain of the receiving antenna

$\mathrm{G}_{\mathrm{t}}-$ gain of the transmitting antenna

$\lambda$ - wavelength of the wave

$\mathrm{R}$ - distance between the transmitter and receiver

This equation relates the power received at a distance to the transmitted power. The received power is inversely proportional to the square of the distance. Thus, the farther you go from a transmitter, the amount of power received decreases quadratically. The available RF power at any location depends on how far the location is from the transmitting station. The spatial distribution of transmitting stations varies from city to city and as a result each city has a unique distribution of power in various frequency bands. In the following section, the results of RF power survey across multiple cities are studied. This information will help determine the general trend of available RF power across various frequency bands. 


\subsubsection{Study of ambient RF power survey}

In the study of RF power surveys there is a common trend of surveying frequencies between $800-1000 \mathrm{MHz}, 1700-1900 \mathrm{MHz}$ and $2400-2500 \mathrm{MHz}$. This makes sense because these frequencies are used for cellular communication and it is a service used by the majority of the population making it an active contributor in the total ambient RF power. The surveys studied below are from three different countries, China, Canada and Singapore. The radio frequency spectrum is allocated for use in different countries differently. However, the bands used for cellular communications by different countries often coincide. For example, the frequencies between 746-956 MHz are used for cellular communication in Canada ${ }^{[35]}, 790-960 \mathrm{MHz}$ are used for cellular communication in Singapore ${ }^{[34]}$ and frequencies between $825-960 \mathrm{MHz}$ are used for cellular communication in China ${ }^{[33]}$. For the United States, frequencies between 698-894MHzare used for cellular communication ${ }^{[6]}$. As it can be seen, all these frequencies coincide in a range of 8001000MHz. The above-mentioned frequencies aren't the only frequencies used for cellular communication, and some other places where they coincide are in the range of 17001900MHz. The frequencies between $2300-2500 \mathrm{MHz}$ are used for cellular communication and other wireless services like Wi-Fi ${ }^{[6][33][34] ~[35] . ~ A s ~ a ~ r e s u l t, ~ s t u d y i n g ~ t h e ~ s u r v e y s ~ d o n e ~}$ in these different regions allows us to determine a general trend of RF power available in a given frequency range. This information can be used to plan a RF power survey on a local level. Andrenko et al. have presented a survey of RF power in Guangdong, China ${ }^{[8]}$. The data from that survey is summarized in Table 2.1 which shows maximum RF power observed at a given location in a given frequency band. 
Table 2. 1: Summary of RF power observed in Guangdong, China ${ }^{[8]}$.

\begin{tabular}{|l|l|l|}
\hline Frequency band $(\mathrm{MHz})$ & $\begin{array}{l}\text { Maximum RF power } \\
\text { observed }(\mathrm{dBm})\end{array}$ & $\begin{array}{l}\text { Location } \\
\text { Information/Notes }\end{array}$ \\
\hline \multirow{2}{*}{$800-1000$} & -38 & Shopping mall \\
\cline { 2 - 3 } & -36 & Residential area \\
\hline \multirow{2}{*}{$1700-1900$} & -55 & Shopping mall \\
\cline { 2 - 3 } & -47 & Residential area \\
\hline $2300-2500$ & -84 & Shopping mall \\
\cline { 2 - 3 } & -64 & Residential area \\
\hline
\end{tabular}

In our second study, a survey of RF power is provided by Kwan et al. for Calgary, Canada ${ }^{[9]}$. They present data collected from various locations providing a valuable insight in the trends of RF power distribution. This data is summarized in Table 2.2.

Table 2. 2: Summary of RF power observed in Calgary, Canada ${ }^{[9]}$.

\begin{tabular}{|l|l|l|}
\hline Frequency band $(\mathrm{MHz})$ & $\begin{array}{l}\text { Maximum RF power } \\
\text { observed }(\mathrm{dBm})\end{array}$ & $\begin{array}{l}\text { Location } \\
\text { Information/Notes }\end{array}$ \\
\hline $800-1000$ & N/A & Home \\
\cline { 2 - 3 } & -22 & Shopping mall \\
\cline { 2 - 3 } & -40 & Park \\
\cline { 2 - 3 } & -34 & Office \\
\cline { 2 - 3 } $1700-2200$ & -24 & University \\
\cline { 2 - 3 } & -25 & Home \\
\cline { 2 - 3 } & -29 & Shopping mall \\
\cline { 2 - 3 } & -35 & Park \\
\cline { 2 - 3 } & N/A & Office \\
\cline { 2 - 3 } & -23 & University \\
\hline $2400-2500$ & -35 & Home \\
\cline { 2 - 3 } & -31 & Shopping mall \\
\cline { 2 - 3 } & -43 & Park \\
\cline { 2 - 3 } & -35 & Office \\
\cline { 2 - 3 } & -29 & University \\
\hline
\end{tabular}


In our third study, Lim et al. provide a survey of RF power on their college campus at Nanyang Polytechnic, Singapore ${ }^{[10]}$. Their data is summarized in Table 2.3.

Table 2. 3: Summary of RF power observed in Nanyang Polytechnic, Singapore ${ }^{[10]}$.

\begin{tabular}{|l|l|l|}
\hline Frequency band $(\mathrm{MHz})$ & $\begin{array}{l}\text { Maximum RF power } \\
\text { observed }(\mathrm{dBm})\end{array}$ & $\begin{array}{l}\text { Location } \\
\text { Information/Notes }\end{array}$ \\
\hline $800-1000$ & -36 & College campus \\
\hline $1700-1900$ & -30 & \\
\hline
\end{tabular}

As seen from Table 2.1-Table 2.3 the RF power is presented in $\mathrm{dBm}$. Sometimes it is helpful to get a different perspective by expressing the RF power in Watts. The following Table 2.4 presents various levels of RF power in $\mathrm{dBm}$ and Watts.

Table 2. 4: Power in $\mathrm{dBm}$ and Watts

\begin{tabular}{|l|l|}
\hline Power in $\mathrm{dBm}$ & Power in Watts \\
\hline $0 \mathrm{dBm}$ & $1 \mathrm{~mW}$ \\
\hline$-10 \mathrm{dBm}$ & $0.1 \mathrm{~mW}$ \\
\hline$-20 \mathrm{dBm}$ & $0.01 \mathrm{~mW}$ \\
\hline$-30 \mathrm{dBm}$ & $1 \mu \mathrm{W}$ \\
\hline$-40 \mathrm{dBm}$ & $0.1 \mu \mathrm{W}$ \\
\hline$-50 \mathrm{dBm}$ & $0.01 \mu \mathrm{W}$ \\
\hline$-60 \mathrm{dBm}$ & $1 \mathrm{nW}$ \\
\hline$-70 \mathrm{dBm}$ & $0.1 \mathrm{nW}$ \\
\hline$-80 \mathrm{dBm}$ & $0.01 \mathrm{nW}$ \\
\hline
\end{tabular}

It can be seen from the data presented in all three studies that the range of maximum RF power observed across all frequencies is between $-84 \mathrm{dBm}$ to $-22 \mathrm{dBm}$. From the study presented in Table 2.2 it can be seen that areas of dense population like shopping malls, university have higher levels of maximum RF observed across all three frequency ranges. It shows us that the potential for RF energy harvesting is more in densely populated areas. 


\subsubsection{Manual RF power source}

The FCC has reserved some frequency bands for Industrial, Scientific and Medical purposes. These are called the ISM bands and they are free to use by the public. There are commercially available transmitters that operate at some of these frequencies, for example, the Powercaster transmitter ${ }^{[12]}$ which transmits at $915 \mathrm{MHz}$ Some of the most commonly used ISM frequencies are $434 \mathrm{MHz}, 915 \mathrm{MHz}, 2450 \mathrm{MHz}$. The commercially available transmitters can also be used to power devices with RF energy harvesting capabilities. However, the FCC has imposed some limits ${ }^{[13]}$ on the amount of power that these devices can transmit. The Powercaster comes with a limit of $3 \mathrm{~W}^{[12]}$. These manual sources have a range of about $15 \mathrm{~m}$ within which the received power can be successfully harvested. This would require a lot of these devices to cover a large area. This brings up the cost of initial setup.

\subsection{Block diagram of RF energy harvester}

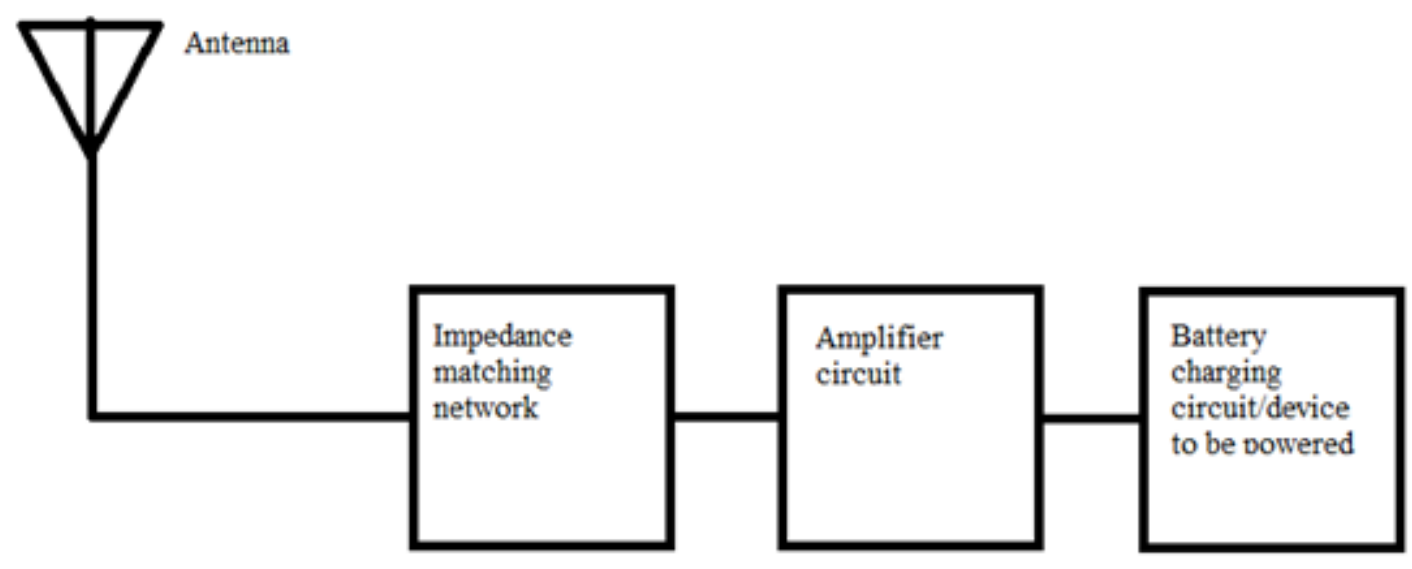

Figure 2. 1: Block diagram of RF energy harvesting device 
The block diagram in Figure 2.1 presents a commonly used architecture for RF energy harvesting devices ${ }^{[11]}$. The antenna responds to the incoming RF power and the impedance matching network ensures maximum power transfer is achieved. The amplifier circuit rectifies and amplifies the voltage of the received signal. It typically consists of voltage multiplying circuits like the Villard voltage doubler or switched capacitor circuit or the Dickson charge pump etc. The final stage is either to charge a battery or to provide power directly to the device to be powered.

\subsection{Amplifier circuit}

The energy harvester needs to be able to harvest energy from as little input power as possible. However, the received power cannot be directly stored on a battery or fed to an application to be powered. This is because, batteries require a specific voltage level to start charging ${ }^{[29]}$ and even some of the low power consuming applications require a specific voltage level for operation ${ }^{[1][2][3][5]}$. The amplifier circuit performs the function of increasing the voltage and provide a path to store the power. The voltage doubler is one of the most commonly used circuit topologies that can help achieve this function. 


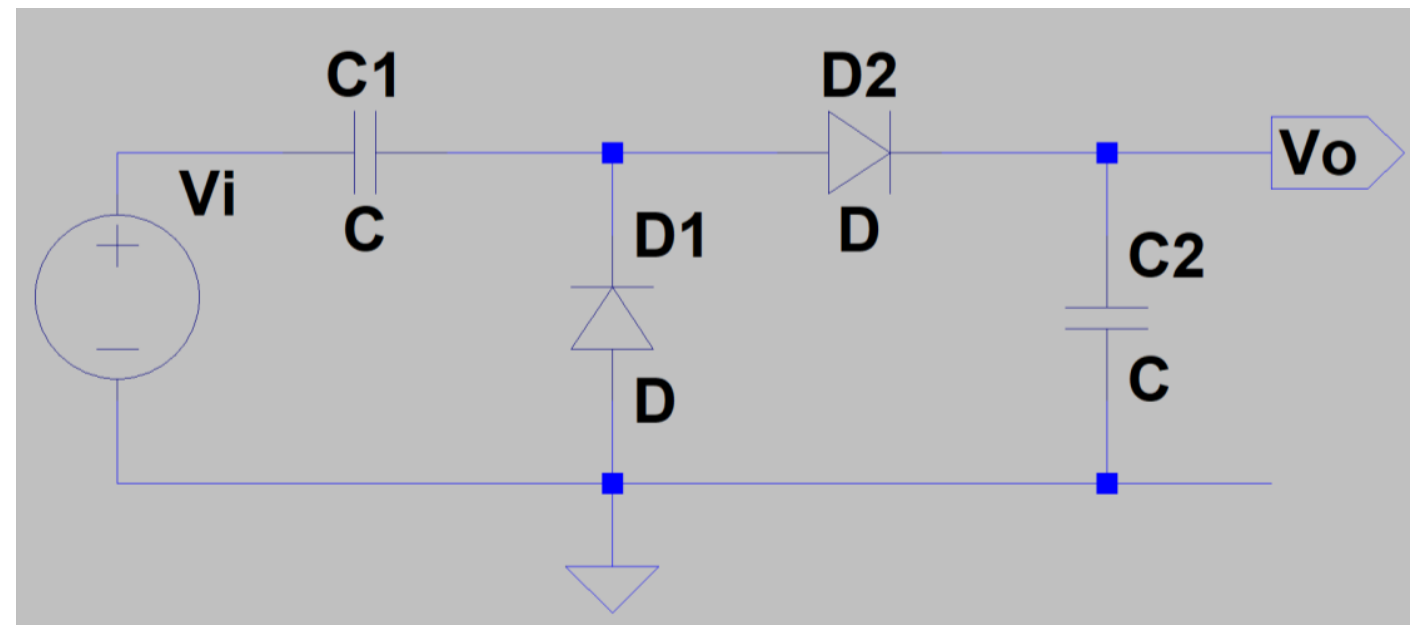

Figure 2. 2: Villard voltage doubler ${ }^{[14]}$

During the negative half cycle of the sinusoidal input waveform, diode D1 is forward biased and thus charges up the capacitor, $\mathrm{C} 1$ to the peak value of the input voltage, Vi. Because there is no path for capacitor $\mathrm{C} 1$ to discharge into, it remains fully charged. At the same time, diode D2 conducts via D1 charging up capacitor, C2. During the positive half cycle, diode D1 is reverse biased blocking the discharging of C1while diode D2 is forward biased charging up capacitor $\mathrm{C} 2$ and providing a path for capacitor $\mathrm{C} 1$ to discharge. But because there is a voltage across capacitor $\mathrm{C} 1$ already equal to the peak input voltage, capacitor $\mathrm{C} 2$ charges to twice the peak voltage value of the input signal. The voltage across capacitor $\mathrm{C} 2$ is the output voltage Vo. Now the diodes have a small voltage drop when they are forward biased so the capacitor $\mathrm{C} 2$ does not reach twice the input voltage.

The output voltage Vo can be expressed as follows:

$$
V o=2(V i-\Delta V)
$$

$\Delta \mathrm{V}=$ voltage drop across the diode 
The output voltage is not instantaneous but increases slowly on each input cycle. As capacitor $\mathrm{C} 2$ only charges up during one half cycle of the input waveform, the resulting output voltage discharged into the load has a ripple frequency equal to the supply frequency. However, the main advantage of this circuit topology is that they can be stacked together in series to provide more voltage boost. The output voltage of an n-stage voltage doubler circuit is given by the following equation.

$$
V o=2 n(V i-\Delta V)
$$

This is assuming that all the diodes used are identical. This same circuit topology can be realized in different ways as shown in Figure 2.3.

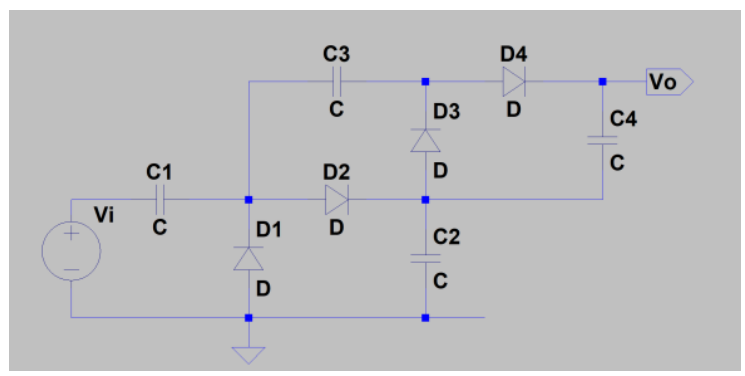

(a)

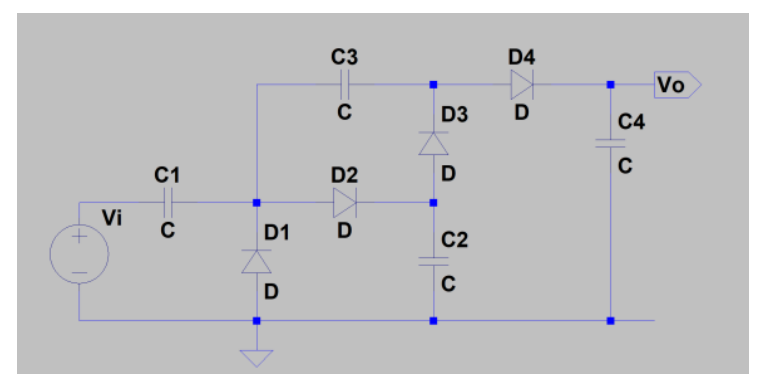

(b)

Figure 2. 3: (a) Villard topology (b) Dickson topology ${ }^{[15]}$

According to ${ }^{[15]}$ the two different topologies do not show any significant difference in performance. However, the diodes available in 8RF technology are not suitable for this design. There are two types of diodes available with 8RF technology, the forward-bias diode and the Schottky barrier diode. The general use of forward biased diodes as circuit elements is not supported in 8RF technology, while the Schottky barrier diode consumes more area on chip than transistors and has higher forward bias voltage than the threshold voltages of some of the transistors offered in 8RF technology. It can be seen from equation 
2.2, higher forward bias voltage decreases the output voltage. Hence, we cannot use this design for our device.

In order to use this concept on an IC, the work in ${ }^{[30]}$ uses floating gate PMOS transistors. This circuit can be seen as a modification of the Villard voltage doubler seen in figure 2.2. The diodes D1 and D2 are replaced by floating gate PMOS transistors M2 and $\mathrm{M} 1$ respectively. The capacitors $\mathrm{C} 1$ and $\mathrm{C} 2$ are realized using diode tied transistor. As seen from equation 2.2 where the output voltage is reduced due to the voltage drop across the diodes. For a transistor-based design the output voltage is reduced due to the threshold voltage of the transistors ${ }^{[30]}$. The floating gate method helps the threshold voltage of the transistors to be programmed, thus helping optimize the output voltage.

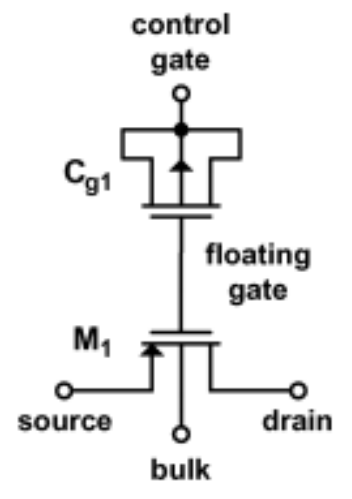

(a)

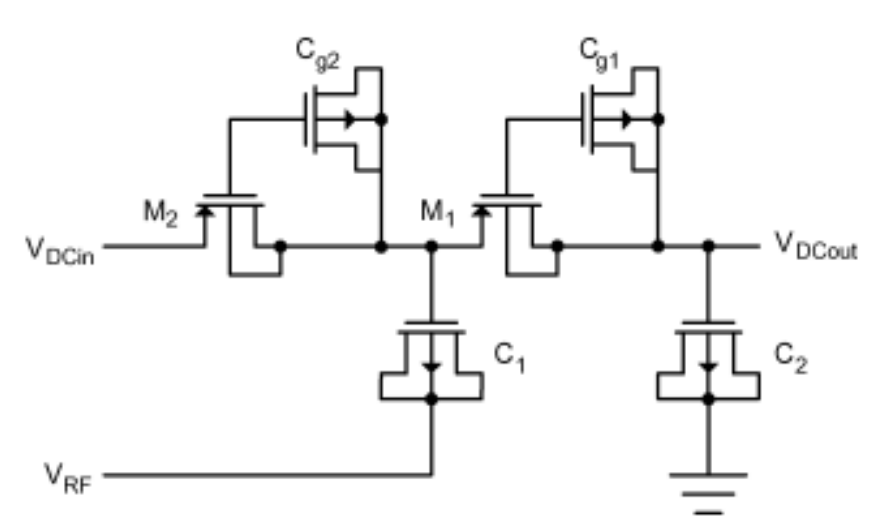

(b)

Figure 2. 4: (a) PMOS floating gate transistor (b) Amplifier using PMOS floating gate transistors ${ }^{[30]}$

To design a floating gate device using just transistors, a capacitor $\mathrm{C}_{\mathrm{g} 1}$ realized using MOSFET, is placed in series with the gate of the diode tied transistor as shown in figure 2.4 (a). The gate of the $\mathrm{M}_{1}$ and $\mathrm{C}_{\mathrm{g} 1}$ form a high-impedance node to trap charges in the floating gate. The charges that are trapped inside the floating gate device act as a gate- 
source bias to passively reduce the effective threshold voltage of the transistor. To create the gate-source bias, a large sinusoidal signal is applied at the input of the rectifier. Charge is injected into the floating gate via the parasitic capacitance between the gate-source and gate-drain junction of the transistor and by hot electron effects. The sinusoidal signal can be applied in pulses with peak voltages between 5-6 V with 2.5-3.0 V DC bias or by a continuous train of signals at lower voltages and bias, depending on the duration of the pulse train ${ }^{[30]}$.

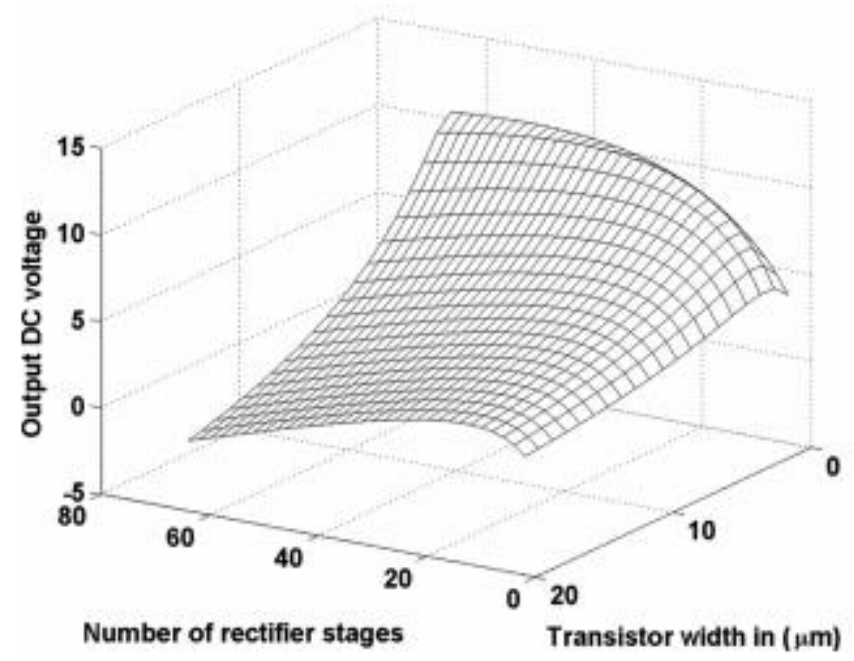

Figure 2. 5: Output voltage vs number of rectifier stages and transistor width ${ }^{\text {[30] }}$

This single stage can be cascaded together to form a multi stage rectifier. Figure 2.5 shows the output voltage plotted as a function of transistor width and the number of rectifier stages for an input voltage of $300 \mathrm{mV}$. This design shows promising results and is compatible with IC technology. However, it requires trigger pulses for start-up and hence it requires additional circuitry. Our aim is to design a self-starting amplifier that does not use any additional circuitry and hence we cannot use this design. 
In order to design a self-starting amplifier that can be practically realized on IC, the work in ${ }^{[16]}$ uses two diode connected NMOS transistors as diodes for the multiplier. This circuit is shown in Figure 2.6. The operation of this circuit is similar to the diode-based circuit discussed in the previous section. This circuit can be stacked in any one of the topologies shown in figure 2.3. The diodes get replaced by diode connected NMOS transistors.

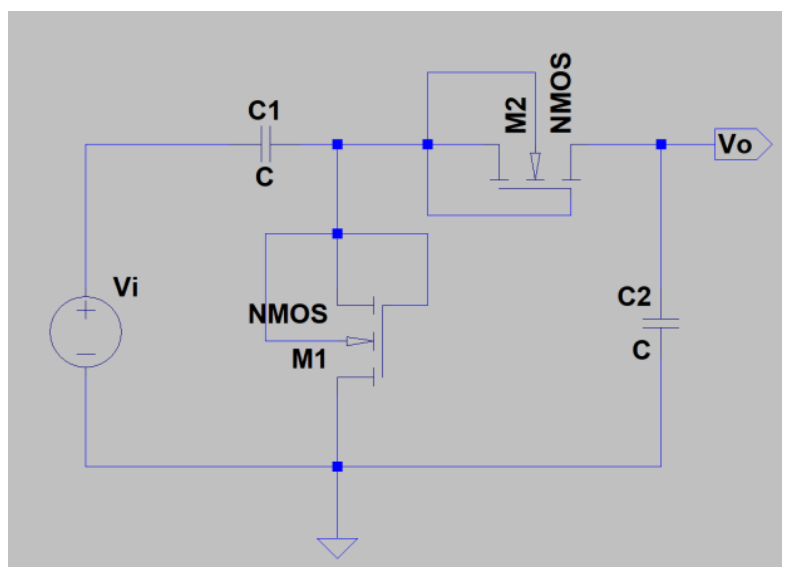

Figure 2. 6: Voltage doubler using gate tied MOSFETs as diodes ${ }^{[16]}$

The output voltage Vo after $\mathrm{n}$ stages is given by the equation 2.4

$$
V o=2 n\left(V i-V_{t h}\right)
$$

$\mathrm{V}_{\mathrm{th}}=$ threshold voltage of NMOS transistor.

The output voltage of this circuit increases slowly on each input cycle. Just like the previous circuit shown in Figure 2.2, this topology too has ripples at the output. But the main advantage of this topology is that it is compatible with the IC fabrication technology. It also provides a significant voltage boost at higher number of stages. 


\subsection{Solid state battery}

The antenna, matching circuit and the amplifier together form an energy harvesting device. It can be used to charge commercially available thin film or solid-state batteries. The Enerchip bare die rechargeable solid-state batteries developed by Cymbet Corporation can be charged with the harvesting device. The EnerChip bare die has two pads with wire bonding facility for co-packaging with other components or onboard chip mounting Figure $2.7^{[29]}$ shows two of the battery models.

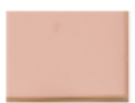

CBCO05

$1.7 \mathrm{~mm} \times 2.25 \mathrm{~mm}$ $\times 0.200 \mathrm{~mm}$

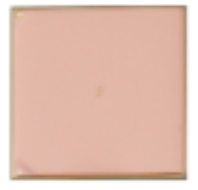

$\mathrm{CBCO50}$

$5.7 \mathrm{~mm} \times 6.1 \mathrm{~mm}$ $\times 0.200 \mathrm{~mm}$

Figure 2. 7: Solid state rechargeable batteries [29]

The CBC005 model offers a charge capacity of $5 \mu \mathrm{Ah}$ and CBC050 offers capacity $50 \mu \mathrm{Ah}$. The batteries have a nominal 3.8V output. They can be recharged with a direct connection to a $4.1 \mathrm{~V}$ voltage source. It does not require any current limiting components. Recharge time averages 20 minutes to $80 \%$ capacity. The battery design offers thousands of charge/discharge cycles. The EnerChip bare die have two wire bondable pads for copackaging with other components or chip-onboard mounting. 


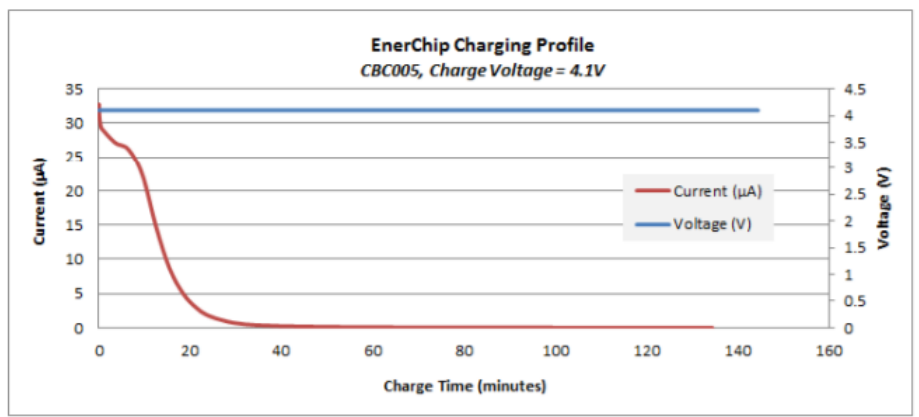

Figure 2. 8: Charging profile of Enerchip CBCO05 [29]

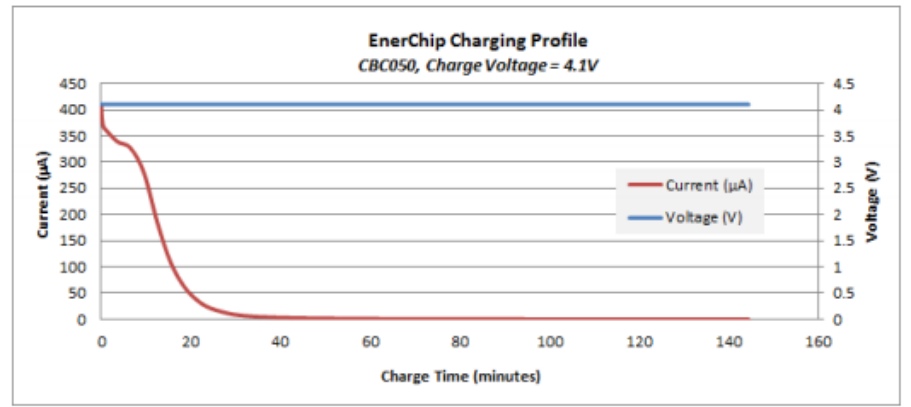

Figure 2. 9: Charging profile of Enerchip CBCO50 [29]

Figure 2.8 and Figure 2.9 show the charging profiles of $\mathrm{CBC} 005$ and $\mathrm{CBC} 050$ models respectively. It can be seen that the $\mathrm{CBC} 005$ requires less current than the $\mathrm{CBC} 050$ owing to its lower capacity. Depending on the output of the amplifier circuit, one of the two batteries may be selected. Table 2.5 lists some of the technical specifications of the batteries.

Table 2. 5: Technical specifications of CBC005 solid state battery ${ }^{\text {[29] }}$

\begin{tabular}{|l|l|l|}
\hline Charge Voltage $\left(25^{\circ} \mathrm{C}\right)$ & $\begin{array}{l}\text { Minimum }=4.0 \mathrm{~V} \\
\text { Maximum }=4.3 \mathrm{~V}\end{array}$ & $\begin{array}{l}\text { Minimum }=4.0 \mathrm{~V} \\
\text { Maximum }=4.3 \mathrm{~V}\end{array}$ \\
\hline $\begin{array}{l}\text { Discharge cutoff voltage } \\
\left(25^{\circ} \mathrm{C}\right)\end{array}$ & $3.0 \mathrm{~V}$ & $3.0 \mathrm{~V}$ \\
\hline $\begin{array}{l}\text { Recharge time (to 80\% of } \\
\text { rated capacity and 4.1V } \\
\left.\text { charge voltage, } 25^{\circ} \mathrm{C}\right)\end{array}$ & $\begin{array}{l}\text { Cycle 2, Min =11 min, Max } \\
=22 \mathrm{~min} \\
\text { Cycle 1000, Min }=45 \mathrm{~min} \\
\mathrm{Max}=70 \mathrm{~min}\end{array}$ & $\begin{array}{l}\text { Cycle 2, Min }=20 \mathrm{~min}, \\
\text { Max }=35 \mathrm{~min} \\
\text { Cycle 1000, Min }=60 \\
\text { min Max }=95 \mathrm{~min}\end{array}$ \\
\hline Capacity & $\begin{array}{l}5 \mu \mathrm{Ah}(40 \mathrm{nA} \text { discharge, } \\
\left.25^{\circ} \mathrm{C}\right)\end{array}$ & $\begin{array}{l}50 \quad \mu \mathrm{Ah} \quad(100 \mu \mathrm{A} \\
\left.\text { discharge, } 25^{\circ} \mathrm{C}\right)\end{array}$ \\
\hline
\end{tabular}




\subsection{Conclusion}

From our study of ambient RF energy surveys, we can say that we can expect to receive up to $10 \mu \mathrm{W}$ of RF power as input. We must harvest this power and generate high enough voltage to either charge a battery or power a low-power circuit. To accomplish this there are various circuit topologies, but the circuit shown in Figure 2.6 uses only NMOS, requires no self-starting circuit and can be realized on the Global Foundries 8RF process and hence we select that circuit to perform the rectification and amplification. 


\section{CHAPTER 3}

\section{RF POWER SURVEY}

\subsection{Study of cellular communication frequency bands}

The Radio Frequency spectrum is divided into various bands by the governing body FCC. Some of the most used part of the RF spectrum lies between $700 \mathrm{MHz}-2400 \mathrm{MHz}$. This is because some bands within this range are used for cellular communication. The FCC divides the country into 734 districts to regulate the cellular frequency bands. We will focus on region 340, San Luis Obispo, CA.

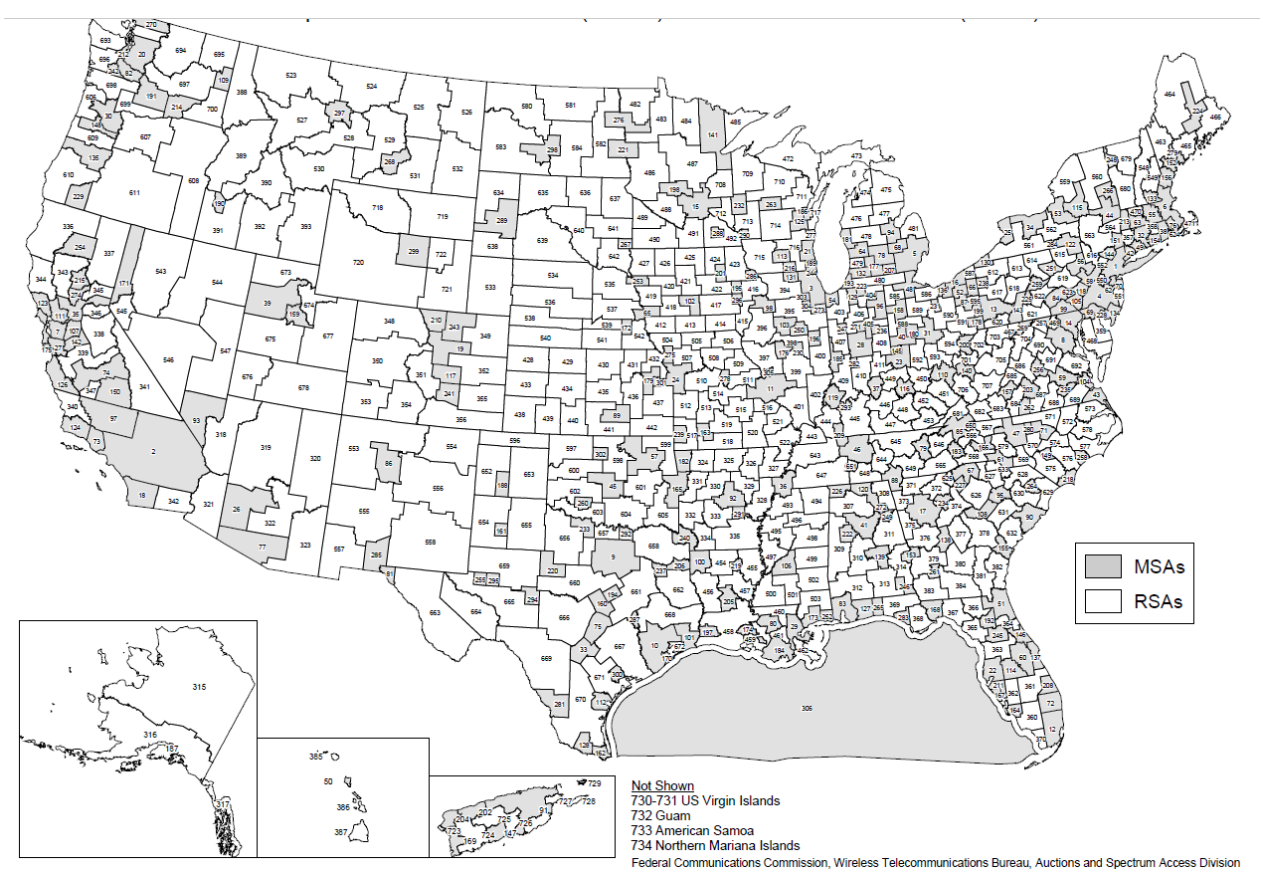

Figure 3. 1: Distribution of 734 districts for frequency regulation across USA ${ }^{\text {[17] }}$

Table 3.1 lists various cellular frequency bands and their owners with respect to region 340 (SLO, CA) This information is useful because it helps us narrow which frequency bands to target. Bands used by cellular companies like AT\&T should in theory 
have more power than some other bands because of the amount of services they offer in the area.

Table 3. 1: List of cellular frequency bands and their corresponding owners ${ }^{\text {[18] }}$

\begin{tabular}{|l|l|l|}
\hline $\begin{array}{l}\text { San Luis Obispo (Region } \\
\text { 340) }\end{array}$ & Frequency $(\mathrm{MHz})$ & Company name \\
\hline Cellular A & $824-849$ & AT\&T \\
\hline Cellular B & $869-894$ & Verizon \\
\hline PCS A & $1850-1865,1930-1945$ & AT\&T, Sprint \\
\hline PCS B & $1870-1885,1950-1965$ & AT\&T, T-Mobile \\
\hline PCS C & $1895-1910,1975-1990$ & FCC \\
\hline PCS D & $1865-1870,1945-1950$ & Entertainment Unlimited \\
\hline PCS E & $1885-1890,1965-1970$ & T-Mobile \\
\hline PCS F & $1890-1895,1970-1975$ & Verizon \\
\hline PCS G & $1910-1915,1990-1995$ & Sprint \\
\hline AWS A & $1710-1720,2110-2120$ & MetroPCS \\
\hline AWS B & $1720-1730,2120-2130$ & Spectrum LLC \\
\hline AWS C & $1730-1735,2130-2135$ & T-Mobile \\
\hline AWS D & $1735-1740,2135-2140$ & MetroPCS \\
\hline AWS E & $1740-1745,2140-2145$ & AT\&T \\
\hline AWS F & $1745-1755,2145-2155$ & T-Mobile \\
\hline Lower 700 A & $698-704,728-734$ & Verizon \\
\hline Lower 700 B & $704-710,734-740$ & FCC \\
\hline Lower 700 C & $710-716,740-746$ & AT\&T \\
\hline Lower 700 D & $716-722$ & Qualcomm \\
\hline Lower 700 E & $722-728$ & Qualcomm \\
\hline Upper 700 C & $746-757,776-787$ & Verizon \\
\hline WCS A & $2305-2310,2350-2355$ & NextWave \\
\hline WCS B & $2310-2315,2355-2360$ & AT\&T \\
\hline WCS C & $2315-2320$ & NextWave \\
\hline WCS D & $2345-2350$ & NextWave \\
\hline
\end{tabular}

Some transmitting base stations were located in SLO city area and the amount of power in various frequency bands were surveyed as listed in Table 3.1. The data collected from different locations will help us study the trends in received RF power levels as we move from one type of area to another. The cell tower location data is available online. The map in Figure 3.2 shows various locations of cellular transmission towers across San Luis Obispo, CA. The goal is to measure the amount of RF power near these towers. This gives 
us a better idea of the available ambient RF power for energy harvesting purposes. Four convenient locations at an adequate distance (50-100m) from these towers are chosen for taking power level readings. Apart from these locations the RF power measurements will be carried out on Cal Poly campus and personal residence located on Murray Avenue. This covers a wide variety of area like academic, residential, suburban etc. The goal is to determine which frequency band is the most promising one to harvest energy from.

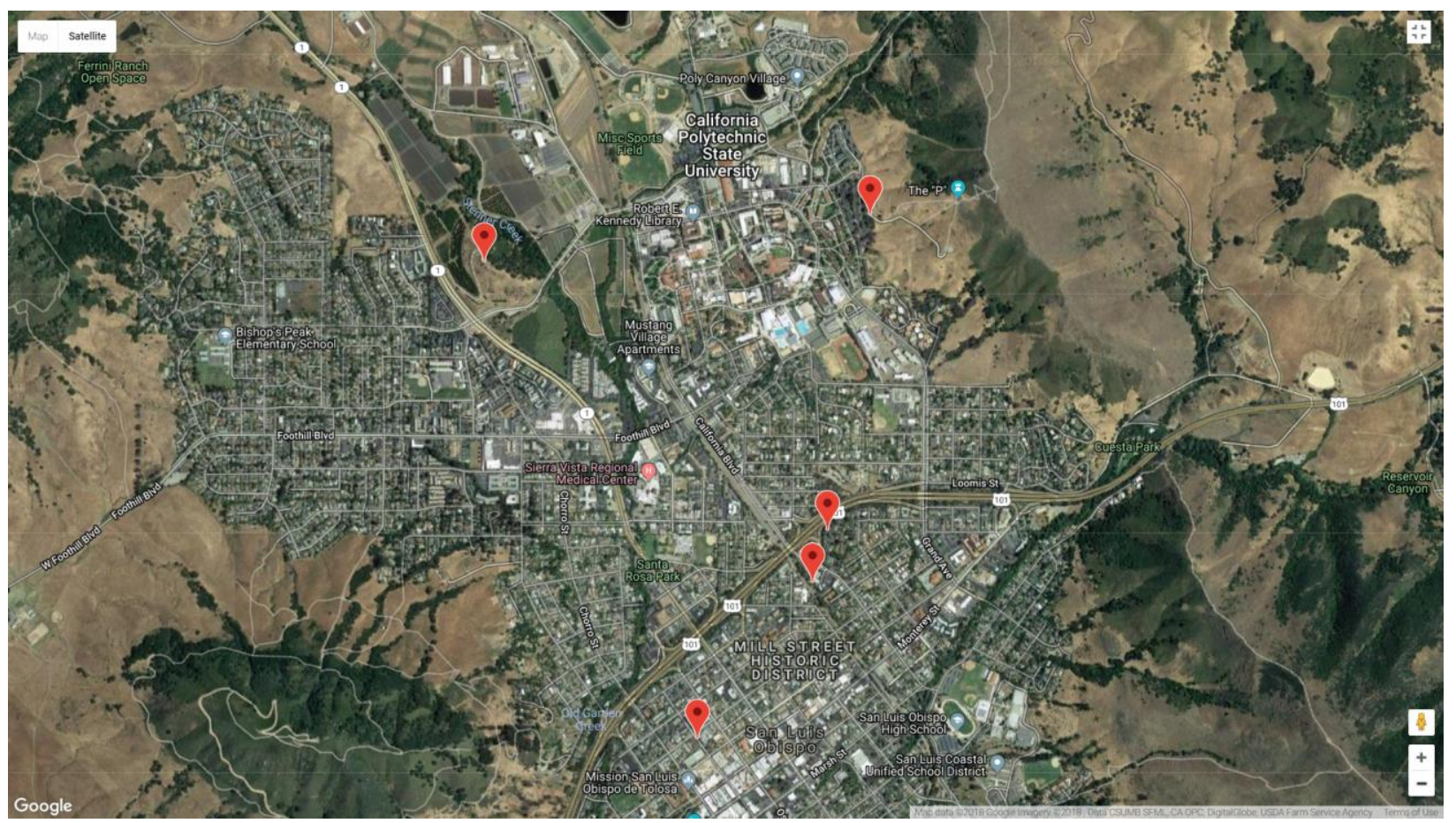

Figure 3. 2: Map showing various locations of cellular transmission towers ${ }^{[19]}$

\subsection{RF power survey across SLO, CA}

The measuring equipment consists of an Anritsu MS2711; a mobile spectrum analyzer and a wideband whip antenna. The setup can be powered via the $12 \mathrm{~V}$ outlet in a car and the antenna rests on the roof of the car. The antenna has a magnetic base to hold it 
in place conveniently on the car roof. Figure

3.3 shows various locations chosen for RF power levels measurement.

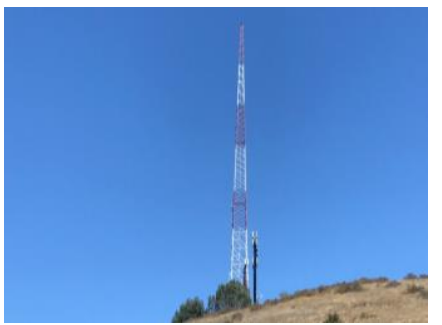

(a)

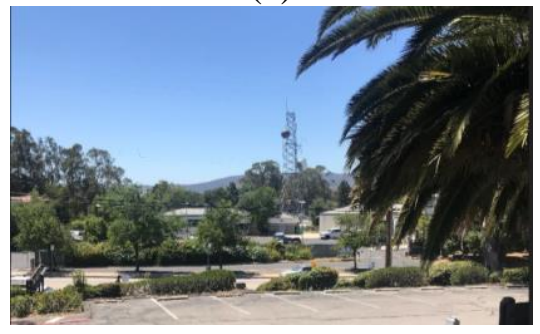

(c)

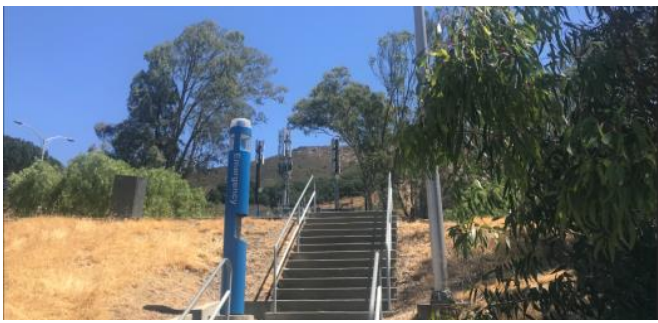

(b)

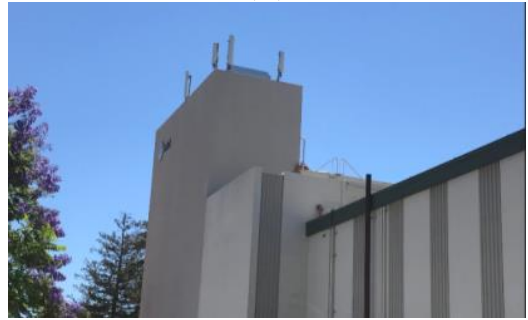

(d)

Figure 3. 3: (a) Highland drive (b) Start of P trail (c) Opposite California Highway Patrol (CHP) (d) Near AT\&T facility

Table 3. 2: Peak RF power averaged over a period of 10 days across each location.

\begin{tabular}{|c|c|c|c|c|c|c|}
\hline \multirow[b]{2}{*}{$\begin{array}{l}\text { Frequency } \\
\text { band }(\mathrm{MHz})\end{array}$} & \multicolumn{6}{|c|}{ Power $(\mathrm{dBm})$} \\
\hline & CAMPUS & HOME & HIGHLAND & $\begin{array}{l}\text { THE } \\
\mathrm{P} \\
\end{array}$ & $\mathrm{CHP}$ & AT\&T \\
\hline $700-800$ & -49.5 & -63.8 & -61.5 & $\begin{array}{r}- \\
49.4 \\
\end{array}$ & -60.5 & -48.3 \\
\hline $820-920$ & -44.5 & -52 & -54.5 & $\begin{array}{r}- \\
47.5 \\
\end{array}$ & -61.8 & -54.6 \\
\hline $1700-1800$ & -64.2 & -75.2 & -74.7 & $\begin{array}{r}- \\
74.8 \\
\end{array}$ & -55.8 & -74.2 \\
\hline $1900-2000$ & -60.2 & -75.3 & -74.9 & $\begin{array}{r}- \\
41.7\end{array}$ & -72.7 & -75 \\
\hline $2100-2200$ & -50.5 & -77.2 & -79.7 & 61.5 & -78.8 & -59.5 \\
\hline $2300-2400$ & -28.8 & -60.9 & -79.8 & 61.3 & -76.6 & -75.8 \\
\hline
\end{tabular}


The summary of peak power averaged over a period of 10 days ( 3 readings per day) across each location is presented in Table 3.2. The power levels shown in red are the highest power levels observed in a given frequency band. From the above data we can see that the $2300-2400 \mathrm{MHz}$ band on campus shows the highest amount $(-28 \mathrm{dBm}$ average peak power) of power available for harvesting. It can be safely said that the prominent use of Wi-Fi in the university is an important contributor to the RF power in that band. Based on this we can safely assume that there would be a similar case in corporate office environments. It can be seen from Table 2.2 that similar power levels are observed in Calgary, Canada. Apart from that frequency band, the 820-920MHz frequency band shows decent amount of RF power close to $-45 \mathrm{dBm}$. From the RF energy surveys studied, it can be seen from Table 2.1-Table 2.3 that the $800-1000 \mathrm{MHz}$ band shows power levels between $-30 \mathrm{dBm}$ to $-40 \mathrm{dBm}$. Figure 3.4 shows the measured peak power levels across San Luis Obispo for frequencies between 820-920 MHz and 2300-2400MHz.

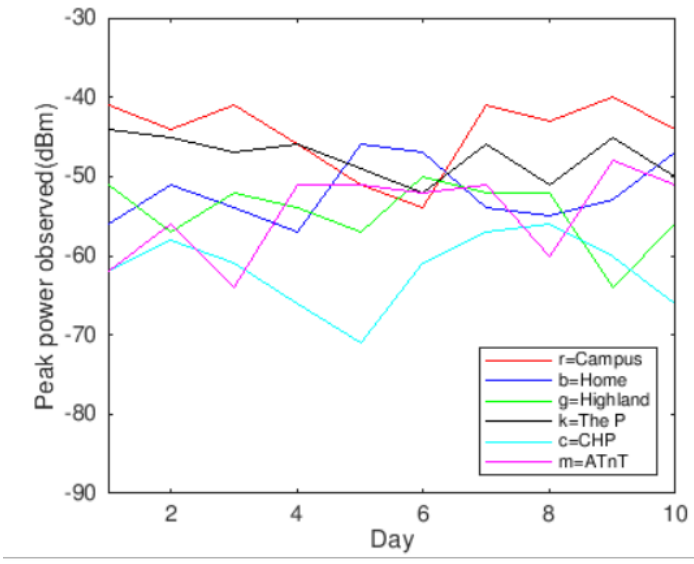

(a)

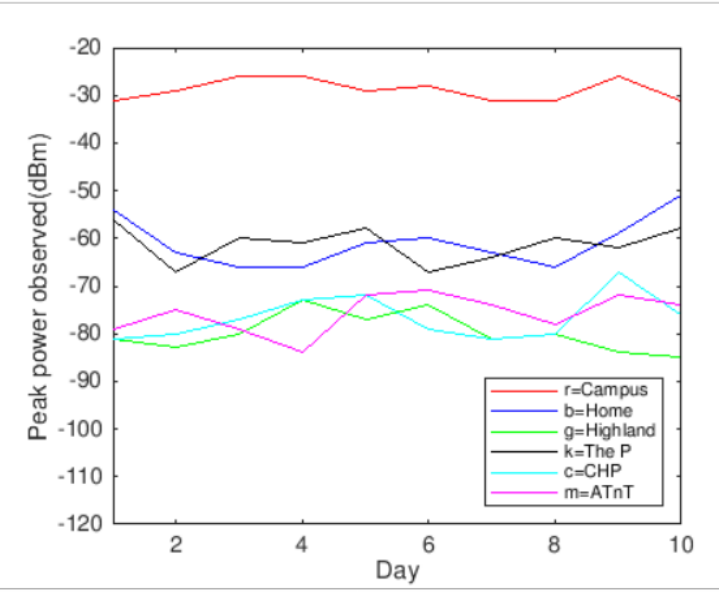

(b)

Figure 3. 4: (a) Peak RF power measured across San Luis Obispo over 10 days for frequencies between $820-920 \mathrm{MHz}(b)$ Peak RF power measured across San Luis Obispo over 10 days for frequencies between 2300-2400M $\mathrm{Hz}$ 


\subsection{Conclusion}

It can be seen from the data presented in this chapter and the literature survey that the $820-920 \mathrm{MHz}$ and the $2300-2400 \mathrm{MHz}$ show the maximum amount of RF power for harvesting. The frequencies between $820-920 \mathrm{MHz}$ include the ISM band with center

frequency $915 \mathrm{MHz}{ }^{[6]}$. The ISM band with center frequency $2.45 \mathrm{GHz}$ is close to the $2300-$ $2400 \mathrm{MHz}$ band. The location of ISM bands close to the frequencies which carry RF input power levels between $-30 \mathrm{dBm}$ to $-40 \mathrm{dBm}$ is beneficial for us because if the device is in a place with low levels of ambient power we can switch to manual power transmission. This type of flexibility is helpful for applications where Quality of Service must be maintained. Using this data, we design two receiving antennae, one with a center frequency of $915 \mathrm{MHz}$ and other with a center frequency of $2400 \mathrm{MHz}$ and a bandwidth of approximately $100 \mathrm{MHz}$. This way we can take advantage of the ambient RF power and have the option of switching to manual power transmission if required. 


\section{CHAPTER 4}

\section{ANTENNA DESIGN}

\subsection{Antenna geometry}

According to the data obtained from literature survey and RF power survey in SLO, it is decided to make two antennae, one with center or resonant frequency $915 \mathrm{MHz}$ and one with $2.4 \mathrm{GHz}$. It is important to note that the size of RF energy harvester should be brought down as much as possible for it to be practical to use. Thus, it is decided to use a patch antenna with for the RF energy harvester. The major advantage of a microstrip antenna is that it can be traced on a printed circuit board. It is very thin, practically a $2 \mathrm{D}$ structure. It occupies less volume than the monopole, dipole, horn antenna etc. Figure 4.1 ${ }^{[7]}$ shows the geometry of a patch antenna.

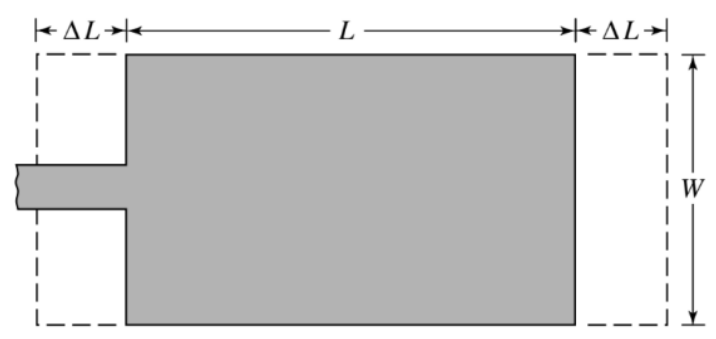

(a)

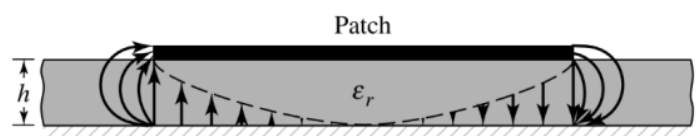

(b)

Figure 4. 1: (a) Top view of the patch (b) Side view of the patch ${ }^{[7]}$

A patch antenna consists of a thin strip of metal of length $\mathrm{L}$ and width $\mathrm{W}$, placed on dielectric medium which rests on the ground plane. The length $\mathrm{L}$ of the patch is a major parameter that helps determine the resonant frequency of the antenna. The thickness of the metal strip and thickness of the dielectric medium should be very less than the resonant wavelength. 


\subsection{Antenna parameters calculation}

The design of a patch antenna begins with determining a good substrate. The dielectric constant of the substrate should be low, and thickness of the substrate should be high for better efficiency ${ }^{[7]}$. However, thicker substrates have higher amount of surface waves. Surface waves do not radiate and are attenuated through the dielectric which causes loss of power and efficiency ${ }^{[7]}$. The most commonly used FR4 substrate is selected due to its low dielectric constant. It has a dielectric constant of 4.4. The substrate comes in various levels of thickness, so we can choose a value that gives us high efficiency. The dimensions of the patch antenna to be designed are given by the following set of equations. These equations are derived in ${ }^{[7]}$.

$$
\begin{gathered}
W=\frac{1}{2 f r \sqrt{\mu_{0} \varepsilon_{0}}} \sqrt{\frac{2}{\varepsilon_{r}+1}} \\
\varepsilon_{r e f f}=\frac{\varepsilon_{r}+1}{2}+\frac{\varepsilon_{r}-1}{2}\left[1+12 \frac{h}{W}\right]^{-\frac{1}{2}} \\
\Delta L=0.412 h \frac{\left(\varepsilon_{\text {reff }}+0.3\right)\left(\frac{W}{h}+0.264\right)}{\left(\varepsilon_{\text {reff }}-0.258\right)\left(\frac{W}{h}+0.8\right)} \\
L=\frac{1}{2 f r \sqrt{\varepsilon_{\text {reff }} \mu_{0} \varepsilon_{0}}}-2 \Delta L
\end{gathered}
$$

$\mathrm{W}=$ Width of the patch, $\mathrm{L}=$ Length of the patch, $\Delta \mathrm{L}=$ Length of the extension $\mathrm{f}_{\mathrm{r}}=$ Resonant frequency of the antenna, $\varepsilon_{\mathrm{r}}=$ Dielectric constant of the substrate $\varepsilon_{\text {reff }}=$ Effective dielectric constant of the substrate, $\mathrm{h}=$ thickness of the dielectric 
This design shows the microstrip feedline connected to the edge of the patch. The feedline can be modified to move into the patch by a distance R. This modified antenna has lower input impedance and hence higher current. The reduced impedance is given by equation $4.5^{[7]}$

$$
Z_{\text {in }}=\cos ^{2}\left(\frac{\pi R}{L}\right) Z_{0}
$$

$\mathrm{Z}_{\text {in }}=$ Input impedance of modified feedline

$\mathrm{Z}_{0}=$ Input impedance of feedline at the edge of the patch

$\mathrm{h}=1.5 \mathrm{~mm}, \varepsilon_{\mathrm{r}}=4.4$

Table 4. 1: Calculated dimensions of both the antennas to be designed.

\begin{tabular}{|c|c|c|}
\hline Parameter & $915 \mathrm{MHz}$ & $2.4 \mathrm{GHz}$ \\
\hline $\mathrm{W}$ & $99.77 \mathrm{~mm}$ & $38 \mathrm{~mm}$ \\
\hline $\mathrm{L}$ & $76.88 \mathrm{~mm}$ & 28.72 \\
\hline$\Delta \mathrm{L}$ & $0.7 \mathrm{~mm}$ & $0.7 \mathrm{~mm}$ \\
\hline $\mathrm{R}$ & $10 \mathrm{~mm}$ & $6 \mathrm{~mm}$ \\
\hline
\end{tabular}

\subsection{Antenna design and simulation on ADS}

The dimensions of the antenna to be designed are calculated from the given equations. The calculated values are showed in Table 4.1. The dimensions are calculated for a patch antenna with feed on the edge. To design and simulate the antenna, Advanced Design System software is used. While using the software for simulation, the feedline is modified to move into the patch by a distance $\mathrm{R}$. This helps reduce the antenna dimensions and adjust input impedance. Figures $4.2-4.9$ show the designed antennas and their characteristics vs frequency. 


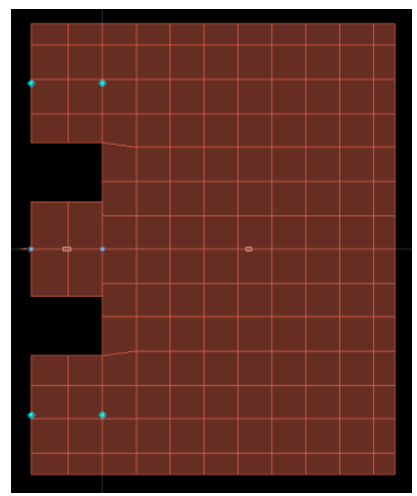

(a)

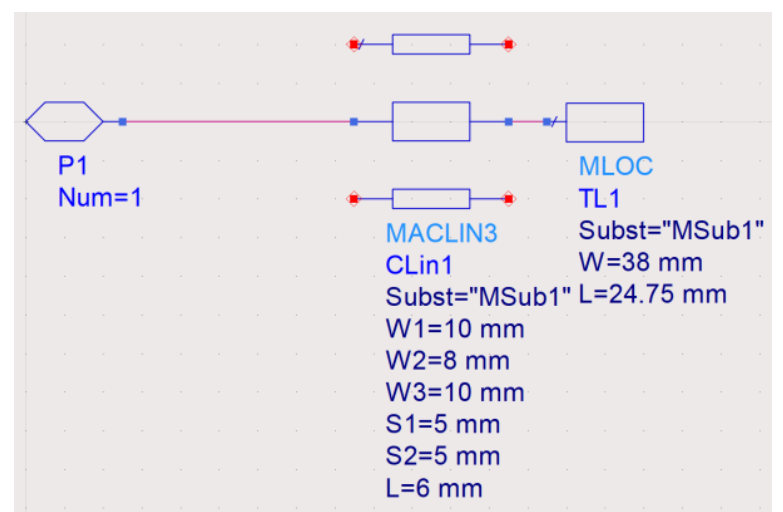

(b)

Figure 4. 2: 2.4GHz patch antenna (a) layout of antenna (b) schematic of antenna

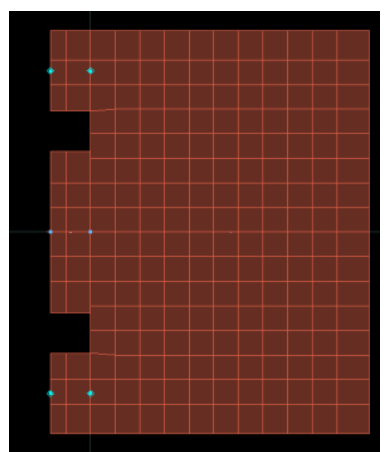

(a)

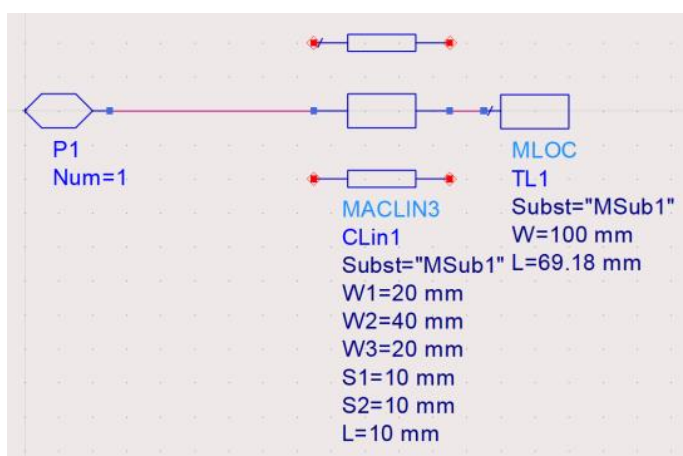

(b)

Figure 4. 3: $915 \mathrm{MHz}$ patch antenna (a) layout of antenna (b) schematic of antenna

Figure 4.2 shows layout and schematic of the $2.4 \mathrm{GHz}$ antenna. The antenna simulation is started with the calculated dimensions and then the dimensions are adjusted during the simulation to obtain desired bandwidth and center frequency. The feedline is $6 \mathrm{~mm}$ long and $8 \mathrm{~mm}$ wide. It has an impedance of $37.59 \Omega$. Figure 4.3 shows layout and schematic of the $915 \mathrm{MHz}$ antenna. The feedline for this antenna is $10 \mathrm{~mm}$ long and $40 \mathrm{~mm}$ wide. It has an impedance of $6.7 \Omega$. 


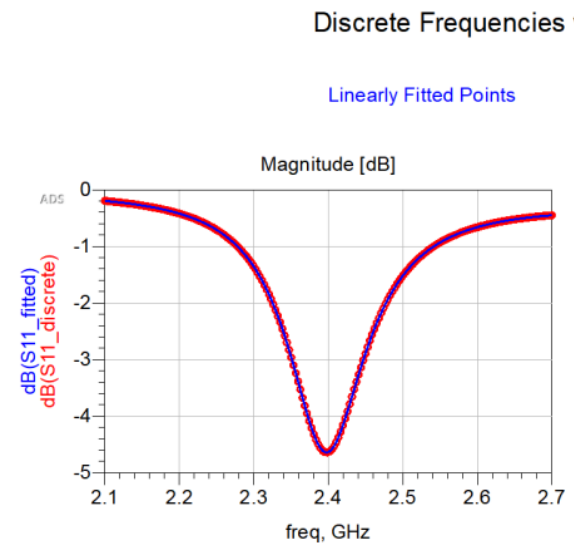

. Fitted (AFS or Linear)

Discrete Frequency Points

Figure 4. 4: Magnitude and Phase plots for 2.4GHz antenna

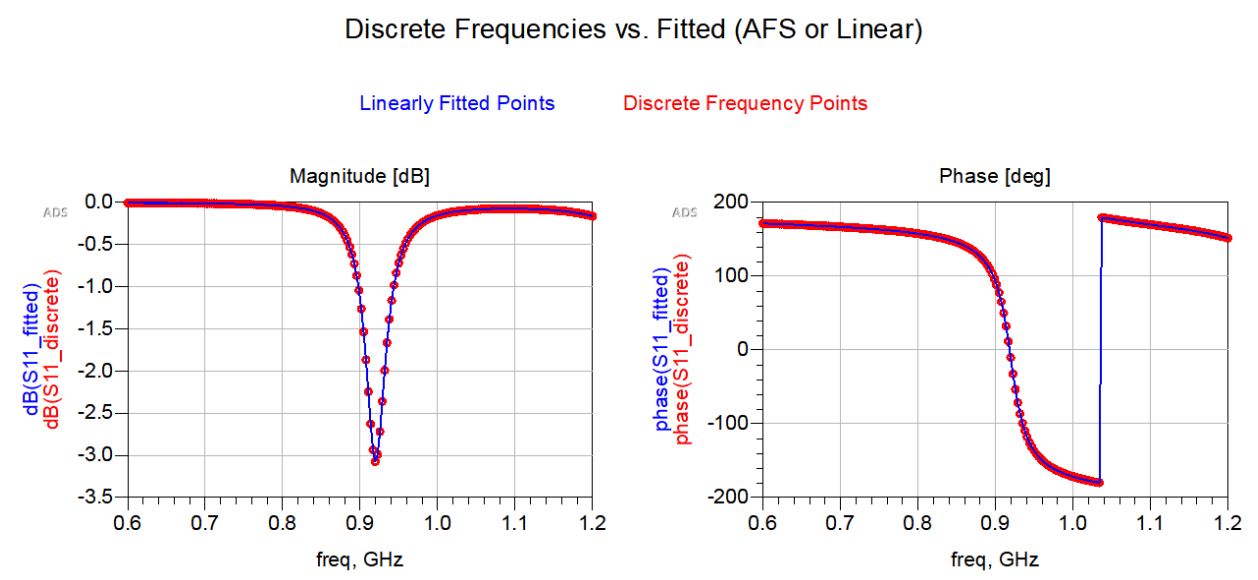

Figure 4. 5: Magnitude and Phase plots for $915 \mathrm{MHz}$ antenna

Figure 4.4 and Figure 4.5 show the magnitude and phase plots for $2.4 \mathrm{GHz}$ and 915 $\mathrm{MHz}$ antenna respectively. To obtain the magnitude and phase plots, the S-parameter S11 is plotted against frequency. S11 represents the amount of power reflected from the antenna. For an $\mathrm{S} 11$ of $-3 \mathrm{~dB}$, if $2 \mathrm{~dB}$ power is incident on the antenna then $-1 \mathrm{~dB}$ is reflected. The rest of the power is absorbed and radiated by the antenna. It can be seen from Figure 4.4 that the power reflected at $2.4 \mathrm{GHz}$ is $-4.6 \mathrm{~dB}$. This is because the antenna is designed to resonate at $2.4 \mathrm{GHz}$ and therefore the reflected power is minimum. A similar observation 
from Figure 4.5 shows that the power reflected at $915 \mathrm{MHz}$ is $-3 \mathrm{~dB}$. If $\mathrm{S}_{11}$ is 0 then it means all power incident on the antenna is reflected back. The antenna does not radiate at frequencies where $S_{11}$ is $0 \mathrm{~dB}$. This helps us determine the bandwidth of the antenna. The 2.4GHz antenna has non-zero $\mathrm{S}_{11}$ from $2.1 \mathrm{GHz}-2.7 \mathrm{GHz}$ and the $915 \mathrm{MHz}$ antenna has nonzero $S_{11}$ from $800-1000 \mathrm{MHz}$. It can be seen that the farther you go from the resonant frequency, the reflected power increases. It is therefore desirable to operate in a given frequency range to minimize reflection losses.

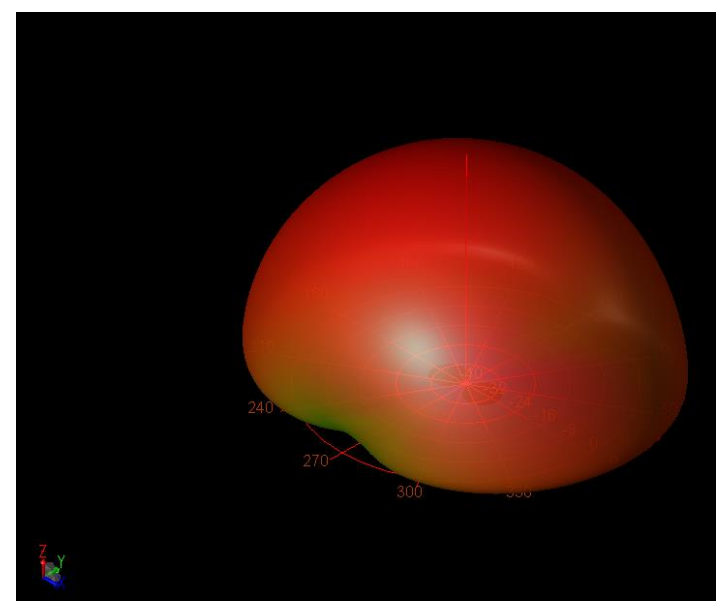

Figure 4. 6: $3 \mathrm{D}$ view of far field radiation pattern for $2.4 \mathrm{GHz}$ antenna

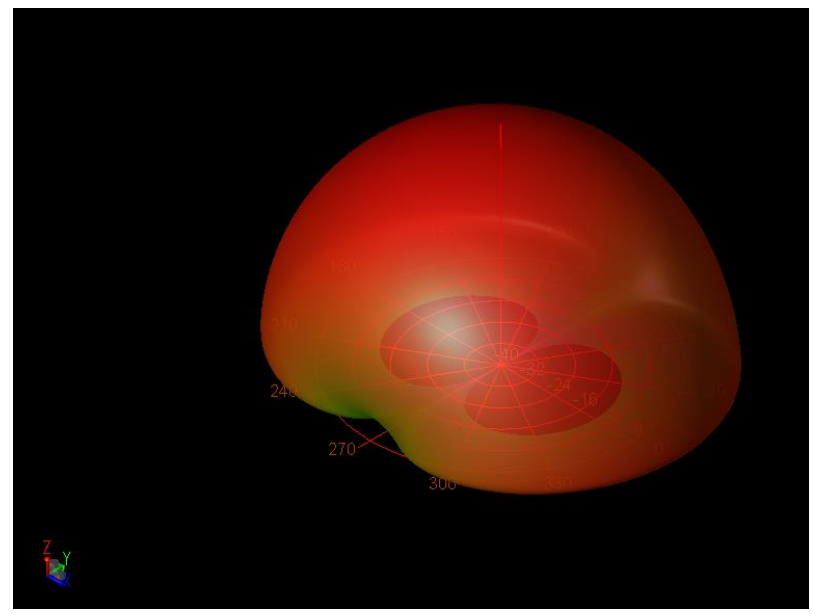

Figure 4. 7:3D view of far field radiation pattern for $915 \mathrm{MHz}$ antenna 
Balainis ${ }^{[7]}$ defines far field radiation pattern as "a mathematical function or a graphical representation of the radiation properties of the antenna as a function of space coordinates". ADS is used to plot the magnitude of electric field as a function of cartesian coordinates. This helps us understand the radiation properties of the antenna. Figure 4.6 and Figure 4.7 show the 3D view of far field radiation pattern for $2.4 \mathrm{GHz}$ and $915 \mathrm{MHz}$ antenna respectively. Both antennas have a hemisphere shaped radiation pattern. This is because there is a ground plane below the microstrip patch antenna and all the radiation is blocked in that direction. This property of patch antenna allows it to be installed on walls and flat surfaces while it radiates in the direction normal to the surface without losing power into the surface.

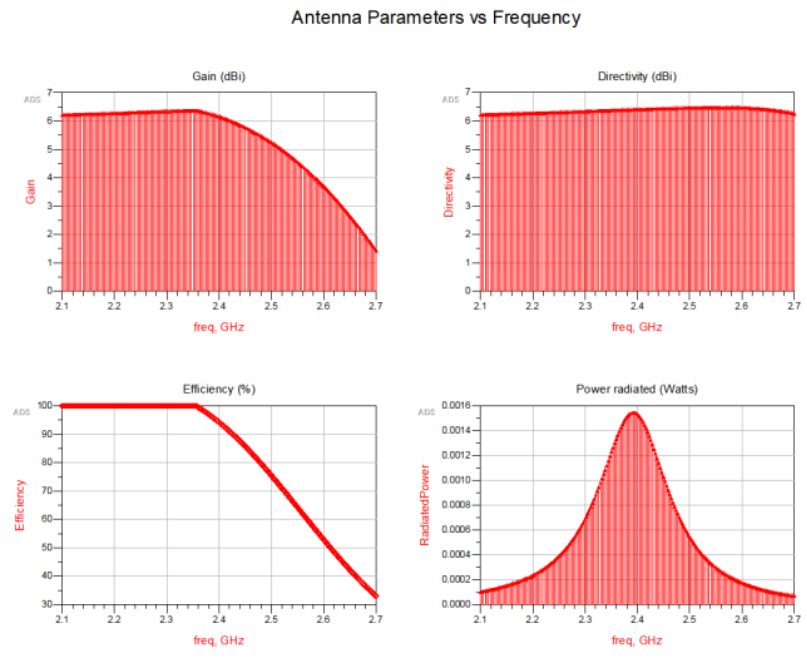

Figure 4. 8: Antenna parameters vs frequency for $2.4 \mathrm{GHz}$ antenna 

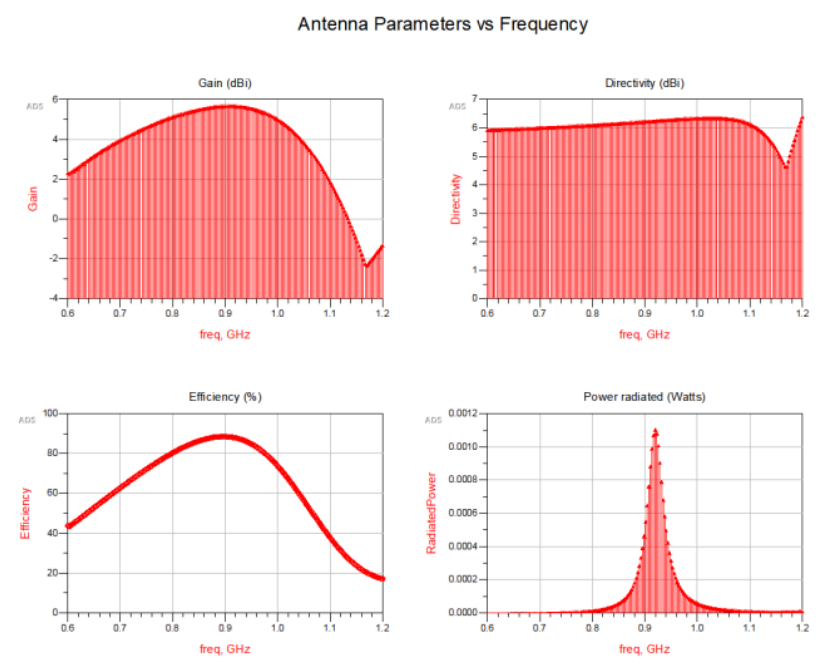

Figure 4. 9: Antenna parameters vs frequency for $915 \mathrm{MHz}$ antenna

Figure 4.8 and 4.9 shows the antenna parameters for $2.4 \mathrm{GHz}$ and $915 \mathrm{MHz}$ antenna respectively. This shows us the relationship of gain, directivity and efficiency. Directivity is a measure of how 'directional' an antenna's radiation pattern is. An antenna that radiates equally in all directions has zero directionality, and the directivity of this type of antenna is $1(0 \mathrm{~dB})$. Antenna efficiency represents the losses of antenna. It includes losses due to mismatch and conductive and dielectric losses. The gain of an antenna is the product of its directivity and efficiency. This is much helpful because it considers the losses in the antenna. Patch antennas generally have directivity of $5 \mathrm{dBi}-8 \mathrm{dBi}{ }^{[7]}$. The $2.4 \mathrm{GHz}$ antenna has a directivity of $6.31 \mathrm{dBi}$, an efficiency of $95 \%$ and a resulting gain of $6.1 \mathrm{dBi}$ at its resonant frequency. The $915 \mathrm{MHz}$ antenna has a directivity of $6.29 \mathrm{dBi}$, an efficiency of $85 \%$ and a resulting gain of $5.4 \mathrm{dBi}$ at its resonant frequency. 
Table 4. 2: Summary of antenna design

\begin{tabular}{|l|l|l|}
\hline Parameter & $915 \mathrm{MHz}$ Antenna & $2.4 \mathrm{GHz}$ Antenna \\
\hline $\begin{array}{l}\text { Overall Dimensions } \\
\text { (W } X \mathrm{~L})(\mathrm{mm})\end{array}$ & $100 \times 79.18$ & $38 \times 30.75$ \\
\hline Desired region of operation & $800 \mathrm{MHz}-1000 \mathrm{MHz}$ & $2300-2500 \mathrm{MHz}$ \\
\hline $\begin{array}{l}\text { Maximum gain in desired } \\
\text { region }\end{array}$ & $5.8 \mathrm{~dB}$ & $6.3 \mathrm{~dB}$ \\
\hline $\begin{array}{l}\text { Minimum gain in desired } \\
\text { region }\end{array}$ & $5 \mathrm{~dB}$ & $5.2 \mathrm{~dB}$ \\
\hline $\begin{array}{l}\text { Maximum efficiency in } \\
\text { desired region }\end{array}$ & $90 \%$ & $99 \%$ \\
\hline $\begin{array}{l}\text { Minimum efficiency in in } \\
\text { desired region }\end{array}$ & $76 \%$ & $75 \%$ \\
\hline
\end{tabular}

Table 4.2 presents the summary of antenna design. The design of the antenna is done considering the RF energy harvesting application. Power harvesting requires antennas with high efficiency ${ }^{[7]}$. The efficiency of designed antennas is above $75 \%$ and goes up to $99 \%$ in the desired region of operation. To provide good gain, the antenna also needs to be directive. However, higher directivity reduces the directions from which we can harvest power. During ambient RF energy harvesting, power needs to be harvested from all possible angles. The designed patch antennas provide a good balance between gain and directivity.

\subsection{Impedance matching}

The impedance matching circuit matches the impedance of the antenna to the amplifier circuit. The input impedance of the amplifier circuit can be of any value. To achieve maximum power transfer, it is necessary to match this impedance with the impedance of the source, which, in this case, is our antenna. Impedance matching is done with the help of the LineCalculator and impedance matching tools in ADS. The LineCalculator tool is used to determine the impedance of the power feeding microstrip 
line which connects the antenna to the rectifier circuit. We can call this our source impedance as it is directly attached to the antenna. The input impedance of the amplifier circuit is the load impedance $\mathrm{Z}$ to be matched with the source impedance. A matching network can be designed to be placed in between the source, antenna and the load, amplifier circuit. ADS impedance matching tools are used to design a matching network.

The first step involves measuring the source impedance and determining a matching network topology. It can be calculated using LineCalculator that the impedance value is $6.75 \Omega$ for a $10 \mathrm{mmX} 40 \mathrm{~mm}$ microstrip feedline used with the $915 \mathrm{MHz}$ antenna. Similar calculation for the $2.4 \mathrm{GHz}$ antenna gives input impedance as $37.59 \Omega$ for an $8 \mathrm{mmX} 6 \mathrm{~mm}$ microstrip feedline used with the antenna. The impedance of the microstrip feedline is resistive in nature.
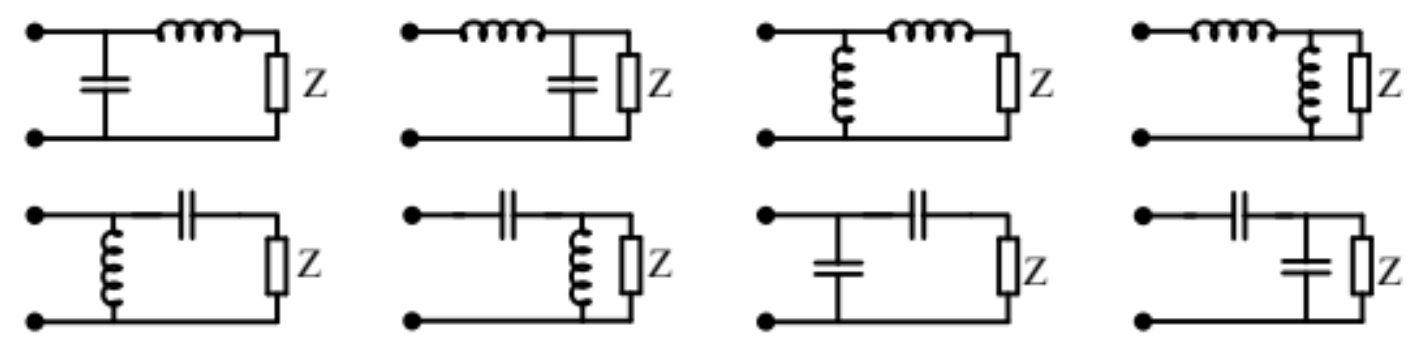

Figure 4. 10: Impedance matching topologies [21]

The simplest way to achieve matching is to use a resistive matching network. Determine the value of the load resistance and add the same value of resistance in parallel across the input of the circuit. It is simple and provides matching at all frequencies. However, the intrinsic noise of the resistors introduces noise at the input ${ }^{[21]}$. Therefore, it is suggested to use reactive components in the matching network. This does not provide 
wideband matching like the resistors, but it also does not introduce as much noise ${ }^{[21]}$. A matching network using reactive components can be designed for a given band of frequencies. We want to achieve impedance matching for a center frequency of $915 \mathrm{MHz}$ or $2.4 \mathrm{GHz}$ depending on the frequency selected to harvest RF power. With the proper choice of two reactive components, any impedance can be matched. There are eight possible two component matching networks, also known as ell networks, shown in Figure 4.10. The selection of a proper matching circuit depends on which circuit provides reasonable component values, personal preference, or stability criteria. In our case, we are working at high frequencies and our main goal is to design a matching network that is also suitable with our power harvesting goals. We require a high pass network, so we cannot choose a circuit where the capacitor is connected to ground because at high frequencies it acts as a short and attenuates all the power received. We select the circuit with series capacitor and parallel inductor shown in Figure 4.11. Z represents load, which in our case is the amplifier circuit.

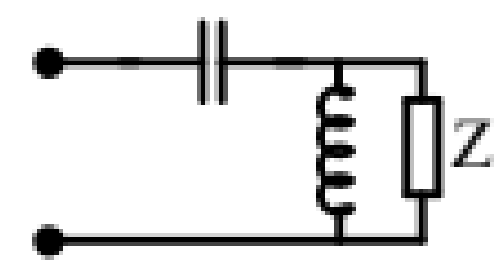

Figure 4. 11: Series Capacitance, parallel inductance matching circuit $^{[21]}$.

Now, the second step in impedance matching is to determine the load impedance. This information, along with the information of the source impedance is used by the impedance matching tools in ADS to automatically design a matching network. It can be seen from figure 5.7 that for our final amplifier design, the input impedance is due to the capacitance of CM0 and channel resistance of NMOS T0 of the first stage voltage doubler. 
The components can be clearly seen in Figure 5.1 which shows single stage voltage doubler. The value of capacitance is designed to be $3.57 \mathrm{pF}$. The channel resistance of the diode connected NMOS is determined using a separate circuit simulated on Virtuoso. Figure 4.12 shows the circuit used to determine channel resistance of NMOS.

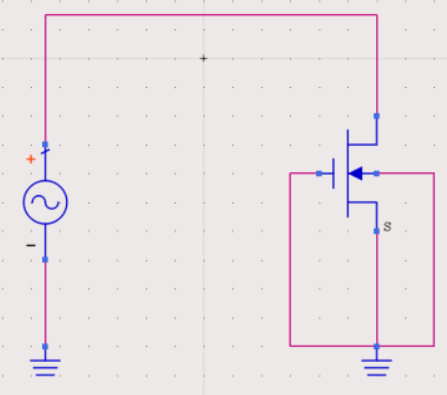

Figure 4. 12: Circuit to determine channel resistance of diode connected NMOS

The circuit is simulated for an input of $500 \mathrm{mV}$ sine wave of frequency $915 \mathrm{MHz}$. The input resistance is calculated using the formula given in equation 4.6. $V(t)$ and $I(t)$ represent the voltage and current across the diode tied NMOS. The Cadence simulator has $\mathrm{N}$ samples of $\mathrm{V}(\mathrm{t})$ and $\mathrm{I}(\mathrm{t})$ stored from time $t_{0}$ to time $\mathrm{t}_{\mathrm{n}}$. The VIVA calculator is used to obtain the value of input impedance. The value of $\mathrm{Z}_{\mathrm{rms}}$ is calculated to be $17.35 \mathrm{k} \Omega$. The input impedance can be modeled with a capacitor of $3.57 \mathrm{pF}$ and a resistance of $17.35 \mathrm{k} \Omega$.

$$
Z_{r m s}=\frac{V_{r m s}}{I_{r m s}}=\frac{\frac{1}{N} \sqrt{\sum_{t=t_{0}}^{t_{n}} V^{2}(t)}}{\frac{1}{N} \sqrt{\sum_{t=t_{0}}^{t_{n}} I^{2}(t)}}
$$


The load and source impedance information along with the desired frequency are used by the ADS impedance matching tools to design a matching network. The circuit topology shown in Figure 4.11 is used for matching network. The values of capacitance and inductance calculated by ADS is shown in Table 4.3.

Table 4. 3: Calculated values of impedance matching components

\begin{tabular}{|l|c|c|}
\hline Center Frequency $(\mathrm{MHz})$ & 915 & 2400 \\
\hline $\mathrm{L}(\mathrm{nH})$ & 60.61 & 53.6 \\
\hline $\mathrm{C}(\mathrm{fF})$ & 498.98 & 82.2 \\
\hline
\end{tabular}

The impedance matching network along with the source resistance and input impedance is modeled in LTSpice. A frequency response plot is derived to ascertain that the matching circuit is operational at desired frequencies.

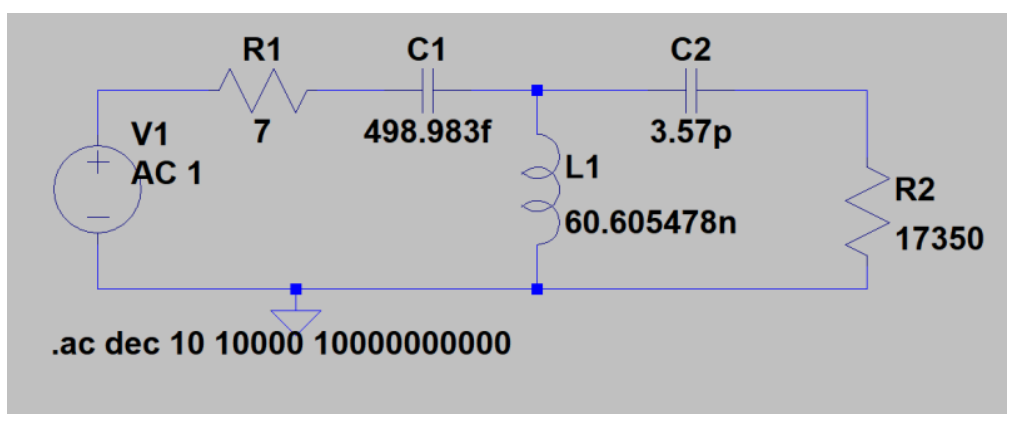

Figure 4. 13: Model of matching network along with the source resistance and input impedance for $915 \mathrm{MHz}$ antenna

In the model shown in Figure 4.13, V1 represents the source, antenna and R1 represents the source impedance which is the resistance of the microstrip feedline. $\mathrm{C} 1$ and L1 form the matching network and $\mathrm{C} 2$ and $\mathrm{R} 2$ represent the input impedance. 


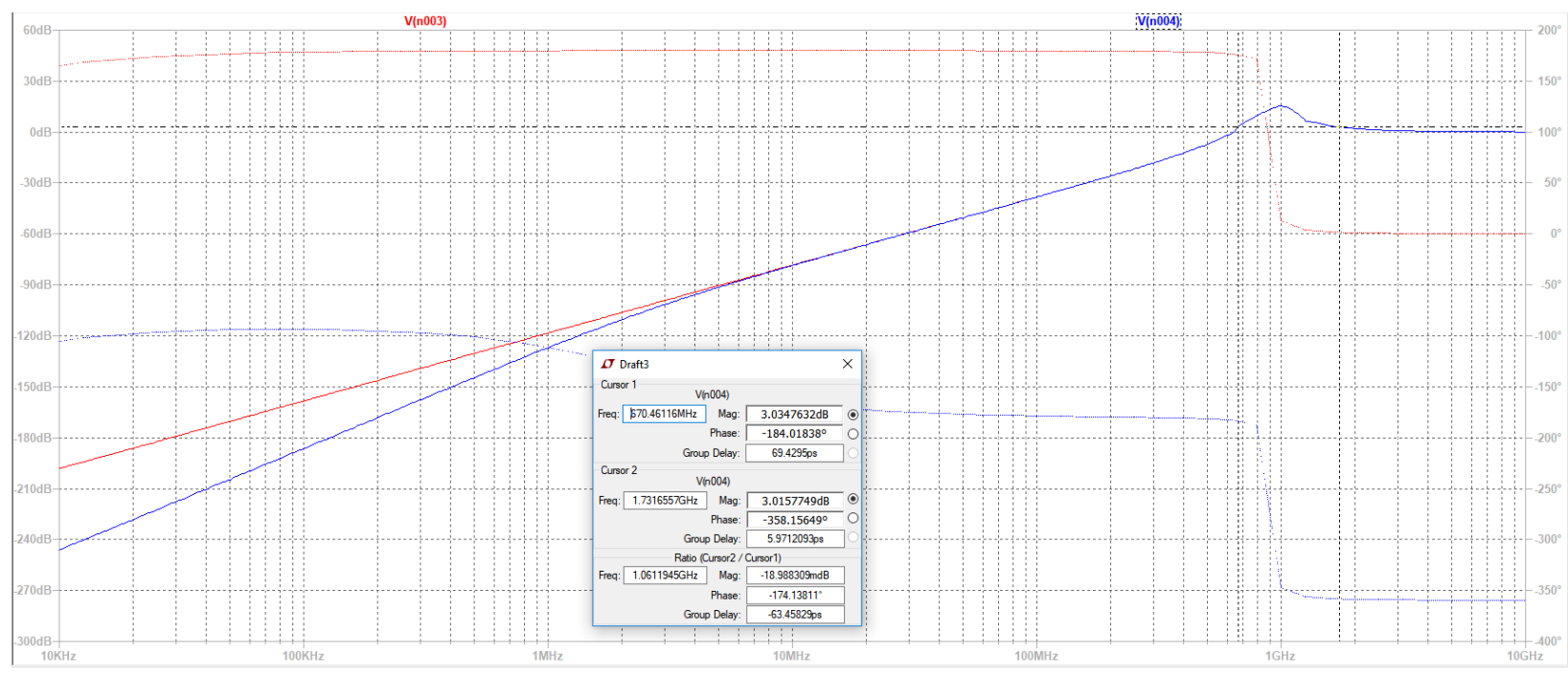

Figure 4. 14: Frequency response of model shown in Figure 4.13

A frequency response plot is shown in Figure 4.14 for the model designed in Figure 4.13. The matching circuit provides a gain of $14 \mathrm{~dB}$ at the resonant frequency $915 \mathrm{MHz}$. The traces in the plot mark the $3 \mathrm{~dB}$ bandwidth of the model. It provides a bandwidth of nearly $1 \mathrm{GHz}$.

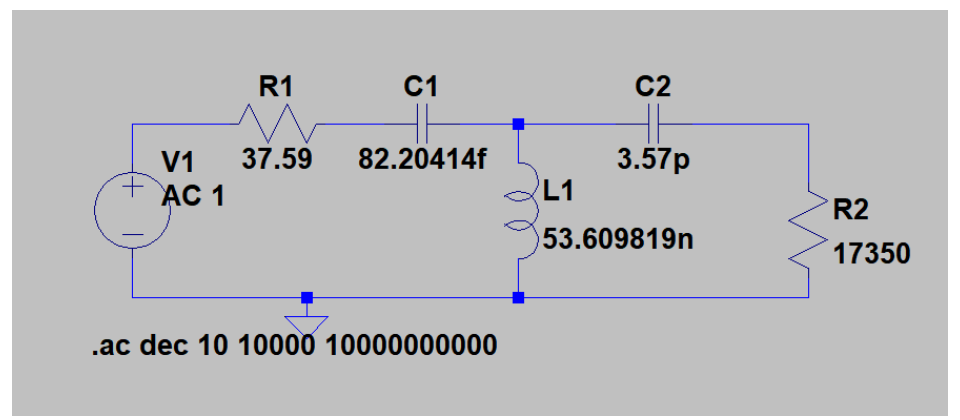

Figure 4. 15: Model of matching network along with the source resistance and input impedance for $2.4 \mathrm{GHz}$ antenna

In the model shown in Figure 4.15, V1 represents the source, antenna and R1 represents the source impedance which is the resistance of the microstrip feedline. $\mathrm{C} 1$ and L1 form the matching network and $\mathrm{C} 2$ and $\mathrm{R} 2$ represent the input impedance. 


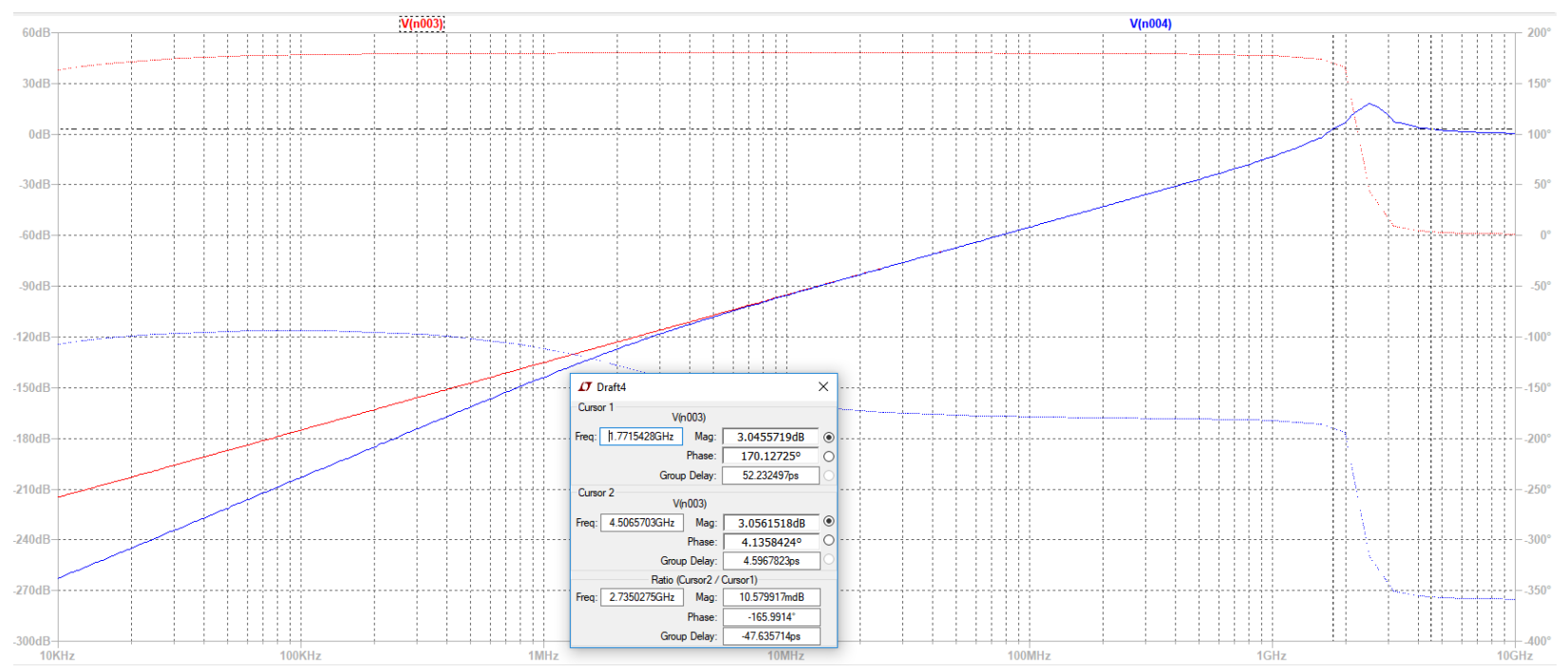

Figure 4. 16: Frequency response of model shown in Figure 4.15

A frequency response plot is shown in Figure 4.14 for the model designed in Figure 4.13. The matching circuit provides a gain of $16 \mathrm{~dB}$ at the resonant frequency $2.4 \mathrm{GHz}$. The traces in the plot mark the $3 \mathrm{~dB}$ bandwidth of the model. It provides a bandwidth of 2.73GHz.

The impedance matching network can be realized either on the IC chip or could be realized as a separate circuit between the antenna and the IC. Having the matching circuit on the IC introduces a couple of issues. The bond wires connecting the IC substrate to the IC package and the I/O pads of the IC introduce their own impedance from its inductance and resistance and as a result the matching with source is not accurate. Having the circuit outside the IC gives us more flexibility over its design. Once the IC is fabricated, the impedance matching network cannot be changed or fine-tuned, however, if it is realized separately off chip then the matching network can be fine-tuned experimentally to include the impedance of the bond wires and the I/O pads. This however, can also introduce 
tolerance issues and the traces to external components introduce their own impedance which is difficult to model. Both approaches have some advantages and disadvantages. However, the size of the inductors used in the matching circuit is larger than most of the highest valued inductors offered by $8 \mathrm{RF}$ process. The inds inductor model offered by the $8 \mathrm{RF}$ process can offer inductance values as high as $70 \mathrm{nH}$. But to achieve the high inductance value, the number of turns of the inductor coil are increased and this introduces a high turn-to-turn parasitic capacitance. As a result, it is decided to design a matching circuit off-chip. 


\section{CHAPTER 5}

\section{AMPLIFIER DESIGN}

The amplifier circuit of the RF energy harvesting device is designed using 130nm CMOS technology. A cascaded voltage doubler circuit must be designed using diode connected NMOS and capacitors. The goal is to achieve an output voltage of up to $4 \mathrm{~V}$, which is enough to charge Enerchip solid-state batteries ${ }^{[29]}$.

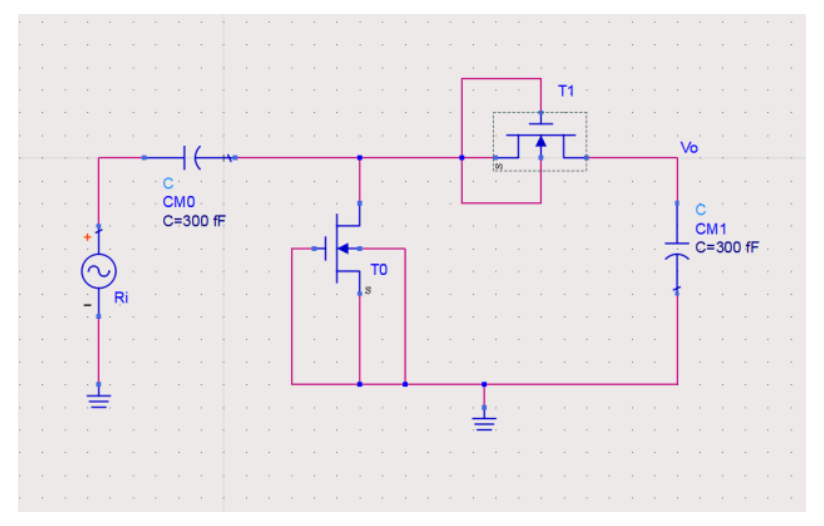

Figure 5. 1: Single stage voltage doubler

\subsection{Circuit Analysis}

The circuit shown in Figure 5.1 is a single stage voltage doubler circuit. The gate, drain and body of transistors are connected. This gives rise to a p-n junction where $\mathrm{n}$ is the source and $\mathrm{p}$ is the body or substrate of the transistor. Based on the orientation of the transistors $\mathrm{T} 0$ and $\mathrm{T} 1$, the diode formed by $\mathrm{T} 0$ is forward biased in the negative half cycle and the diode formed by T1 is forward biased in the positive half cycle The input is assumed to be a sinusoidal waveform, as it is a good approximation of the electromagnetic wave carrying RF power. To analyze the transient response of the circuit, start with the negative half cycle of the sinusoidal input waveform, T0 is forward biased and thus charges up the capacitor, CM0 to the peak value of the input voltage, Vi. Because there is no return 
path for capacitor CM0 to discharge into, it remains fully charged. At the same time, $\mathrm{T} 1$ conducts via T0 charging up capacitor, CM1. During the positive half cycle, T0 is reverse biased blocking the discharging of $\mathrm{CM} 0$ while diode $\mathrm{T} 1$ is forward biased charging up capacitor $\mathrm{CM} 1$ and providing a path for capacitor $\mathrm{CM} 0$ to discharge. But because there is a voltage across capacitor CM0 already equal to the peak input voltage, capacitor CM1 charges to twice the peak voltage value of the input signal. The voltage across capacitor CM1 is the output voltage Vo. However, in practical applications the capacitor CM1 never charges up to twice the input voltage due to the voltage drops across $\mathrm{T} 0$ and T1. Figure 5.2 shows the simulation results of a single stage voltage doubler. The output voltage increases by $45 \%$ over the input voltage.

\subsubsection{Output voltage analysis}

To achieve high efficiency and maximum possible output voltage it is necessary to analyze the circuit shown in figure 5.1 in detail and figure out the factors affecting the

output voltage Vo. The output voltage Vo is given by the following equation $5.1^{[16]}$ and the threshold voltage $\mathrm{V}_{\text {th }}$ is given in equation $5.2^{[28]}$.

$$
V o=2\left(R i-V_{t h}\right)
$$

Vo $=$ Output Voltage, $\mathrm{Ri}=$ Input voltage, $\mathrm{V}_{\mathrm{th}}=$ Threshold voltage of NMOS

$$
V_{t h}=V_{t h 0}+\Upsilon\left(\sqrt{\left|2 \phi+V_{S B}\right|}-\sqrt{|2 \phi|}\right)
$$

$\mathrm{V}_{\mathrm{th} 0}=$ Threshold voltage when $\mathrm{V}_{\mathrm{SB}}$ is $0, \phi=$ Fermi potential, $\mathrm{V}_{\mathrm{SB}}=$ Source-body voltage 
It can be seen from equation 5.1 that one way to maximize the output voltage would be to minimize the threshold voltage of the transistors. Equation 5.2 shows that threshold voltage is increased with an increase in the voltage $\mathrm{V}_{\mathrm{SB}}$ between source and body. In the design presented above, gate and source are tied to the same potential and hence $\mathrm{V}_{\mathrm{SB}}$ is zero. Thus, the threshold voltage is minimized.

\subsubsection{Output current analysis}

It is important to know the current through the NMOS. This helps us determine the output power of the circuit. The drain current of the NMOS transistor is derived by Neamen D. in ${ }^{[27]}$. The current $I_{D}$ for NMOS in the linear region is given by equation $5.3^{[27]}$ and the current in the saturation region is given by equation $5.4^{[27]}$.

$$
\begin{gathered}
I_{D}=\frac{k^{\prime}}{2} \frac{W}{L}\left[2\left(V_{G S}-V_{t h}\right) V_{D S}-V_{D S}{ }^{2}\right] \\
I_{D}=\frac{k^{\prime}}{2} \frac{W}{L}\left(V_{G S}-V_{t h}\right)^{2}
\end{gathered}
$$

$\mathrm{W}=$ Width of the NMOS, $\mathrm{L}=$ Length of the NMOS

$\mathrm{V}_{\mathrm{GS}}=$ Gate to Source voltage, $\mathrm{V}_{\mathrm{DS}}=$ Drain to source voltage

Equation 5.4 gives the current voltage relationship assuming a constant channel length L. However, when the device is operated in saturation region, the channel length $\mathrm{L}$ is not constant. This is because when the NMOS is operating in saturation region, the depletion region near the drain extends laterally into the channel, thus reducing the channel length. Now the width of the depletion region depends on $V_{D S}$ and therefore the effective channel length also depends on $V_{D S}$. This is known as channel length modulation effect. Equation 
5.5 describes the current voltage relationship after incorporating the effects of channel length modulation.

$$
I_{D}=\frac{k^{\prime}}{2} \frac{W}{L}\left(V_{G S}-V_{t h}\right)^{2}\left(1+\lambda V_{D S}\right)
$$

The parameter $\lambda$ is called the channel length modulation parameter. The effect of channel length modulation is more prominent in processes where minimum gate length is below $1 \mu \mathrm{m}$. This is because the reduction in channel length in saturation region of operation is a significant fraction of the original channel length $\mathrm{L}$. The reduction in channel length gives rise to some undesirable effects like the hot electron effect. As the electric field in the drain junction space charge region increases, electron hole pairs are generated by impact ionization. The generated electrons are swept to the drain and the generated holes are swept towards the substrate. Some electrons get attracted to the oxide because of their high energies [27]. This is concerning for thin gate oxides because thin oxides make it easier for the high energy electrons to overcome the potential barrier of the oxide. Sometimes the electrons get trapped in the gate oxide building up the negative charging effect. This increases the threshold voltage of the NMOS. These high energy electrons are known as hot electrons, hence the name hot electron effect. This accumulation of electrons is a continuous process and builds up over time. This causes the device to degrade and deviate from their original properties.

For the diode connected NMOS used in this design, the transistors operate in saturation region. Hence the current is given by equation 5.5. The amount of current $I_{D}$ depends directly on the Width to Length ratio of the transistor. Therefore, we should select a transistor with high $\mathrm{W} / \mathrm{L}$ ratio. This increases the amount of current through the 
transistors and eventually helps in increasing the output current. This helps increase the output power. However, increasing the $\mathrm{W} / \mathrm{L}$ ratio means the transistor will have more width and the space charge depletion region is bigger. This amount of hot electrons generated is more and thus the probability of the electrons getting trapped in the gate oxide increases. We use a low threshold NMOS with thin gate oxide. Therefore, we should strike a balance in deciding the $\mathrm{W} / \mathrm{L}$ ratio. Higher ratio gives us more current but also increases the chances of device degradation. Increasing the W/L ratio also increases the gate oxide capacitance. This is because the capacitance between two plates is directly proportional to area of the plates. Increasing W/L increases the gate width and thus the overall area. This increase in capacitance slows down the device and introduces delays in voltage amplification.

\subsection{RF technology}

The 8RF CMOS technology offers various options of NMOS transistors. Various options available for transistors and capacitors were studied. We need a MOSFET with low threshold voltage and high current. The Low $\mathrm{V}_{\text {th }}$ option provides the lowest threshold voltage. So, the Low $\mathrm{V}_{\text {th }}$ MOSFET is selected for the design.

\subsection{Simulation}

The input RF signal is approximated using a sine wave input of given frequency. Initial simulations are done for $915 \mathrm{MHz}$ and $2.4 \mathrm{GHz}$ separately but it was found that the output voltage and current does not show significant change with the change in frequency. So, all the simulation results shown below are for an input frequency of $915 \mathrm{MHz}$. The input 
voltage discussed from here on refers to peak amplitude of the sine wave. To decide the input voltage, various factors are considered. Initially the various values of incident input voltage are calculated for various values of input power. The values of input power are decided based on the RF power survey. For example, the peak power observed in SLO was around $-30 \mathrm{dBm}$ which corresponds to $1 \mu \mathrm{W}$. Table 5.1 shows the result of these calculations. The formula given in equation 5.6 is used to calculate the input voltage. The value of the input impedance $\mathrm{Z}$ is calculated in section 4.4 .

$$
V=\sqrt{P Z}
$$

Table 5. 1: Input power vs input voltage relationship

\begin{tabular}{|l|l|l|}
\hline Input power $(\mathrm{dBm})$ & Input power $(\mu \mathrm{W})$ & Input voltage $(\mathrm{mV})$ \\
\hline-30 & 1 & 131 \\
\hline-26 & 2.5 & 208 \\
\hline-22 & 6.3 & 331 \\
\hline-18 & 15.8 & 524 \\
\hline-14 & 39.8 & 830 \\
\hline-12 & 63.1 & 1046 \\
\hline
\end{tabular}

The literature survey carried out on similar RF energy harvesting circuits revealed Karolak D. et al. in ${ }^{[16]}$ use an input voltage between $300-500 \mathrm{mV}$ for testing their amplifier circuit. The threshold voltage of the transistor used is also considered. Based on this, the input voltage is decided to be $500 \mathrm{mV}$ for design purposes. This corresponds to an input power of around $-20 \mathrm{dBm}$. The voltage levels for incident power up to $-25 \mathrm{dBm}$ are less than the $\mathrm{V}_{\text {th }}$ of the transistors. Once the circuit is deigned, it will be tested for various input voltages and the corresponding output voltages will be determined. This will help determine the least amount of power that can be used to generate a voltage of up to $4 \mathrm{~V}$. 
The number of voltage doubler stages simulated are increased gradually to study the effect of number of stages on output voltage. An optimum number of stages should be determined based on the output voltage requirements, power requirements and area constraints. The initial W/L ratio is set to $\mathrm{R} 4$. The capacitor value is decided to be $300 \mathrm{fF}$. Low value of capacitance allows the circuit to reach peak output voltage quickly. The transient response of a single stage voltage doubler is shown in figure 5.2. The thick lines representing $\mathrm{Ri}$ is because a $915 \mathrm{MHz}$ sinewave for a duration of 100 micro seconds is shrunk to fit the image. The peak output voltage is $725 \mathrm{mV}$. The output current measured at the terminal of capacitor CM1 is $36 \mu \mathrm{A}$. There is a ripple at the output of about $60 \mathrm{mV}$.

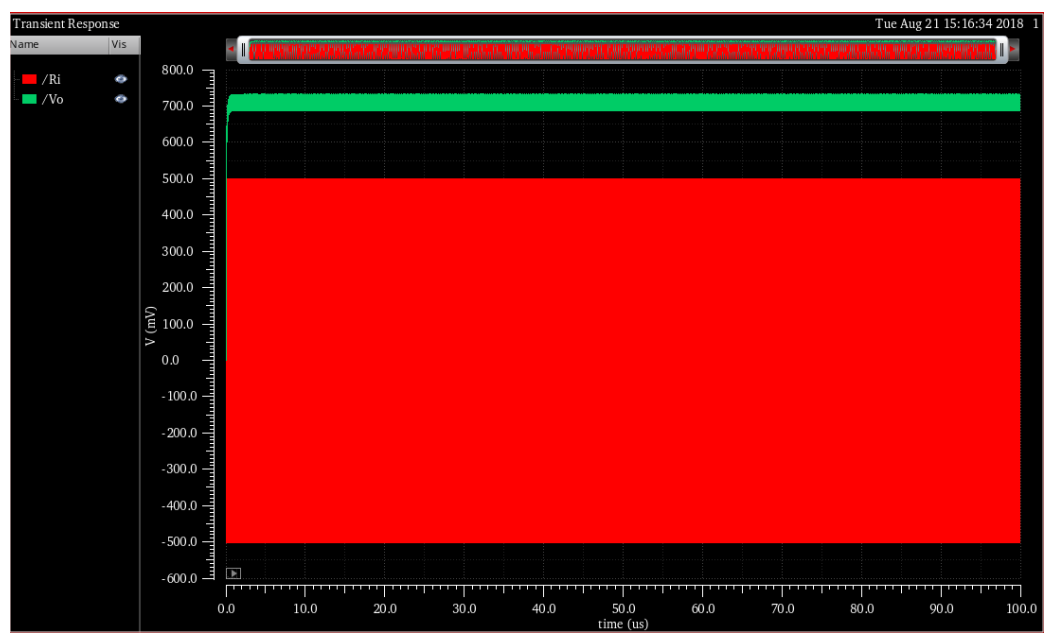

Figure 5. 2: Transient response of single stage voltage doubler

The output voltage increased by $45 \%$ for a single stage voltage doubler. A twostage voltage doubler is simulated under similar conditions. Figure 5.3 shows the schematic of the two-stage voltage doubler. 


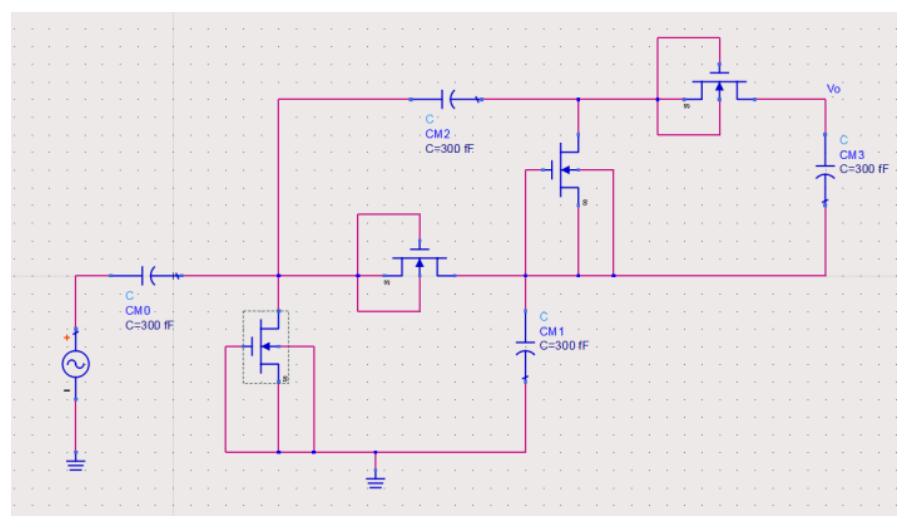

Figure 5. 3: Two stage voltage doubler

The transient response of the two-stage voltage doubler is shown in figure 5.4. The output of first stage is also shown on the plot under the name 'net9'. The peak output voltage is $1.215 \mathrm{~V}$. The ripple in the output voltages increases to $100 \mathrm{mV}$.

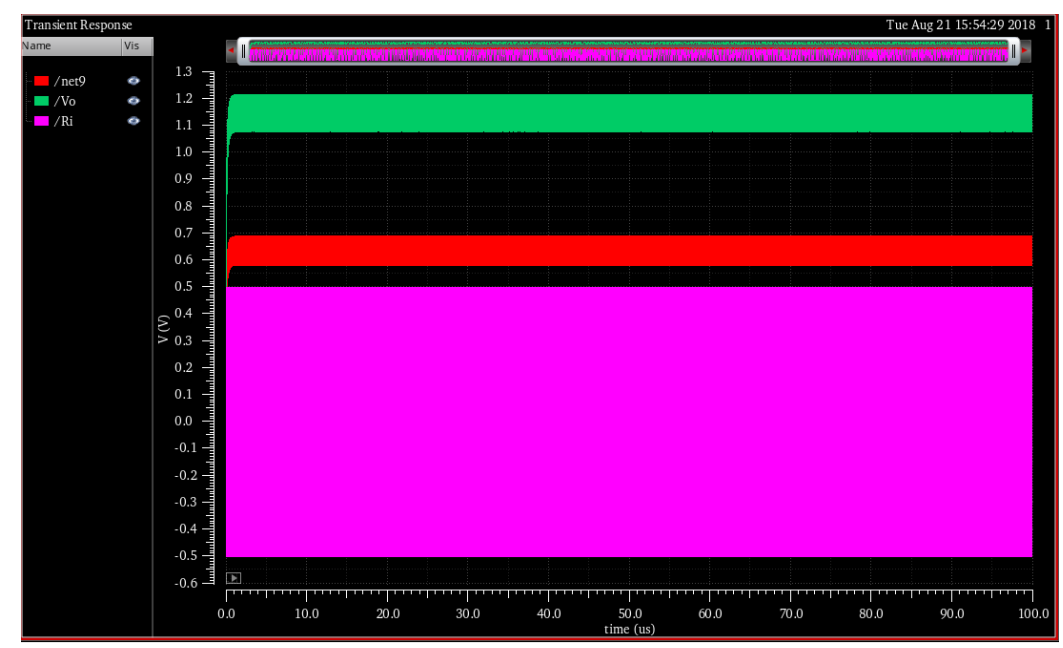

Figure 5. 4: Transient response of two stage voltage doubler

A four-stage voltage doubler shown in Figure 5.5 is simulated under above mentioned conditions. Its transient response is shown in Figure 5.6. The peak output voltage is $1.5098 \mathrm{~V}$. It is important to note that the size of the output ripple increases with 
the number of stages. The output of first stage is shown under 'net9' and the output of second stage is shown under 'net14'.

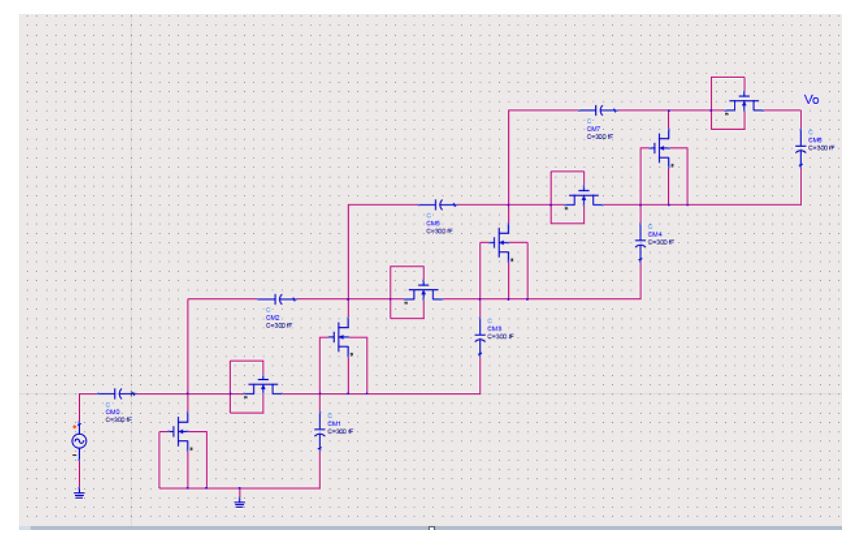

Figure 5. 5: Four stage voltage doubler

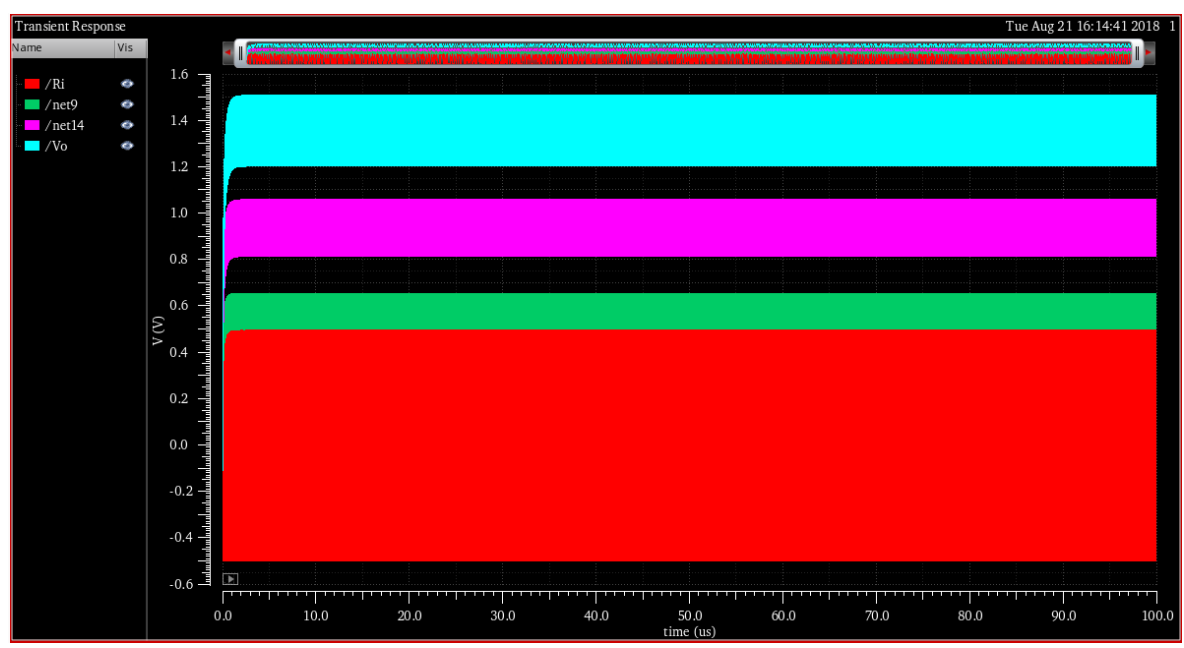

Figure 5. 6 Transient response of four stage voltage doubler

An eight-stage voltage doubler shown in Figure 5.7 is simulated similar conditions as for previous simulations. Its transient response is shown in Figure 5.8. The peak output voltage is $1.4595 \mathrm{~V}$. The output voltage after 8 stages is less than the output voltage after 4 stages. It is important to note that the size of the output ripple is $400 \mathrm{mV}$ peak to peak. 


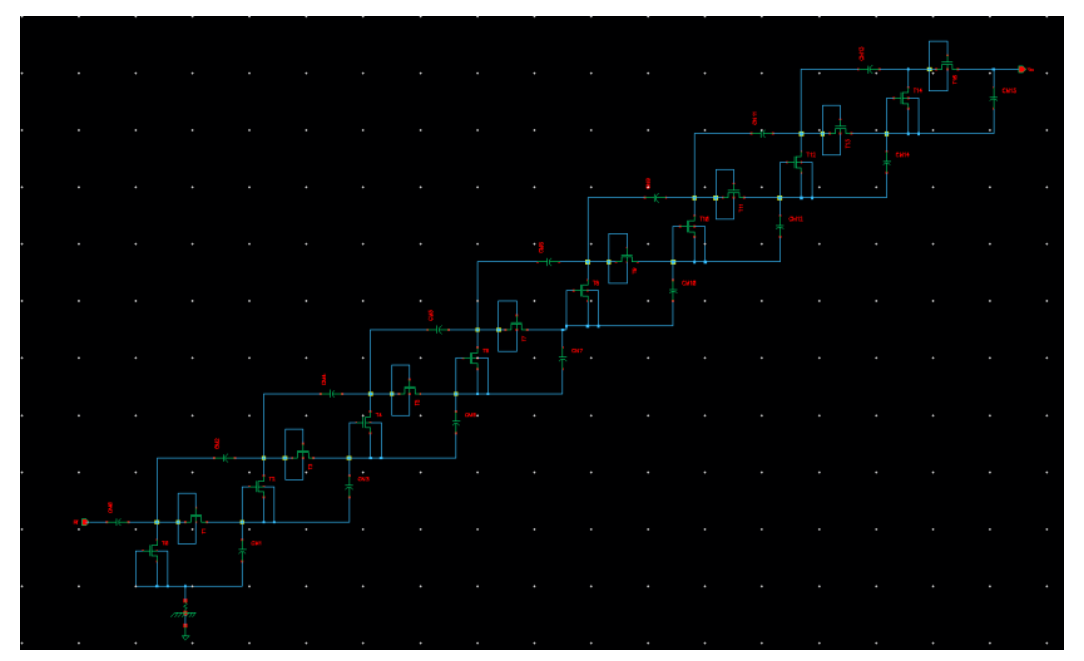

Figure 5. 7: Eight stage voltage doubler

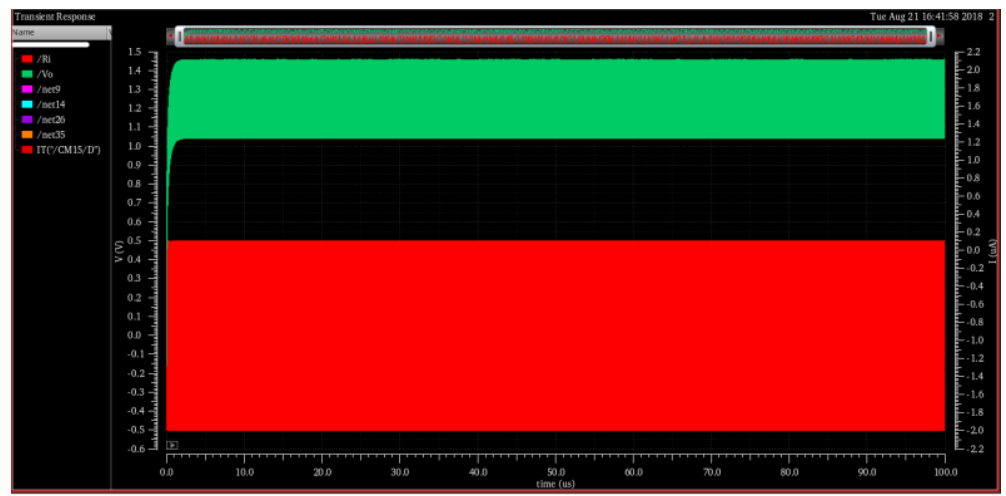

Figure 5. 8: Transient response of eight stage voltage doubler

The eight-stage doubler is simulated a few times varying some key parameters like the $\mathrm{W} / \mathrm{L}$ ratio and the value of $\mathrm{CM} 0$ and $\mathrm{CM} 1$. It is observed from the simulations that a higher value of capacitance can provide better amplification. Increasing the capacitance for the same W/L ratio exhibits a sharp increase in output voltage. The results of this variation are summarized in Table 5.2. The values of current and voltage are the peak values observed and the value for power is the maximum instantaneous power obtained at the output. 
Table 5. 2: Summary of various simulation results

\begin{tabular}{|l|l|l|l|l|}
\hline & $\mathrm{W} / \mathrm{L}=\mathrm{R} 1$ & $\mathrm{~W} / \mathrm{L}=\mathrm{R} 2$ & $\mathrm{~W} / \mathrm{L}=\mathrm{R} 3$ & $\mathrm{~W} / \mathrm{L}=\mathrm{R} 4$ \\
\hline $\mathrm{C}=303 \mathrm{fF}$ & $\mathrm{V}=3.61 \mathrm{~V}$ & $\mathrm{~V}=2.25 \mathrm{~V}$ & $\mathrm{~V}=2.03 \mathrm{~V}$ & $\mathrm{~V}=1.46 \mathrm{~V}$ \\
\hline & $\mathrm{I}=1.82 \mu \mathrm{A}$ & $\mathrm{I}=2.75 \mu \mathrm{A}$ & $\mathrm{I}=2.83 \mu \mathrm{A}$ & $\mathrm{I}=1.20 \mu \mathrm{A}$ \\
\hline & $\mathrm{P}=6.57 \mu \mathrm{W}$ & $\mathrm{P}=6.19 \mu \mathrm{W}$ & $\mathrm{P}=5.74 \mu \mathrm{W}$ & $\mathrm{P}=1.76 \mu \mathrm{W}$ \\
\hline $\mathrm{C}=2.7 \mu \mathrm{pF}$ & $\mathrm{V}=5.25 \mathrm{~V}$ & $\mathrm{~V}=4.72 \mathrm{~V}$ & $\mathrm{~V}=4.57 \mathrm{~V}$ & $\mathrm{~V}=3.90 \mathrm{~V}$ \\
\hline & $\mathrm{I}=3.21 \mu \mathrm{A}$ & $\mathrm{I}=11.01 \mu \mathrm{A}$ & $\mathrm{I}=12.79 \mu \mathrm{A}$ & $\mathrm{I}=21.22 \mu \mathrm{A}$ \\
\hline & $\mathrm{P}=16.85 \mu \mathrm{W}$ & $\mathrm{P}=51.96 \mu \mathrm{W}$ & $\mathrm{P}=58.45 \mu \mathrm{W}$ & $\mathrm{P}=82.75 \mu \mathrm{W}$ \\
\hline $\mathrm{C}=3.5 \mu \mathrm{pF}$ & $\mathrm{V}=5.32 \mathrm{~V}$ & $\mathrm{~V}=4.91 \mathrm{~V}$ & $\mathrm{~V}=4.77 \mathrm{~V}$ & $\mathrm{~V}=4.21 \mathrm{~V}$ \\
\hline & $\mathrm{I}=3.15 \mu \mathrm{A}$ & $\mathrm{I}=11.08 \mu \mathrm{A}$ & $\mathrm{I}=13.82 \mu \mathrm{A}$ & $\mathrm{I}=23 \mu \mathrm{A}$ \\
\hline & $\mathrm{P}=16.79 \mu \mathrm{W}$ & $\mathrm{P}=54.41 \mu \mathrm{W}$ & $\mathrm{P}=65.92 \mu \mathrm{W}$ & $\mathrm{P}=96.6 \mu \mathrm{W}$ \\
\hline
\end{tabular}

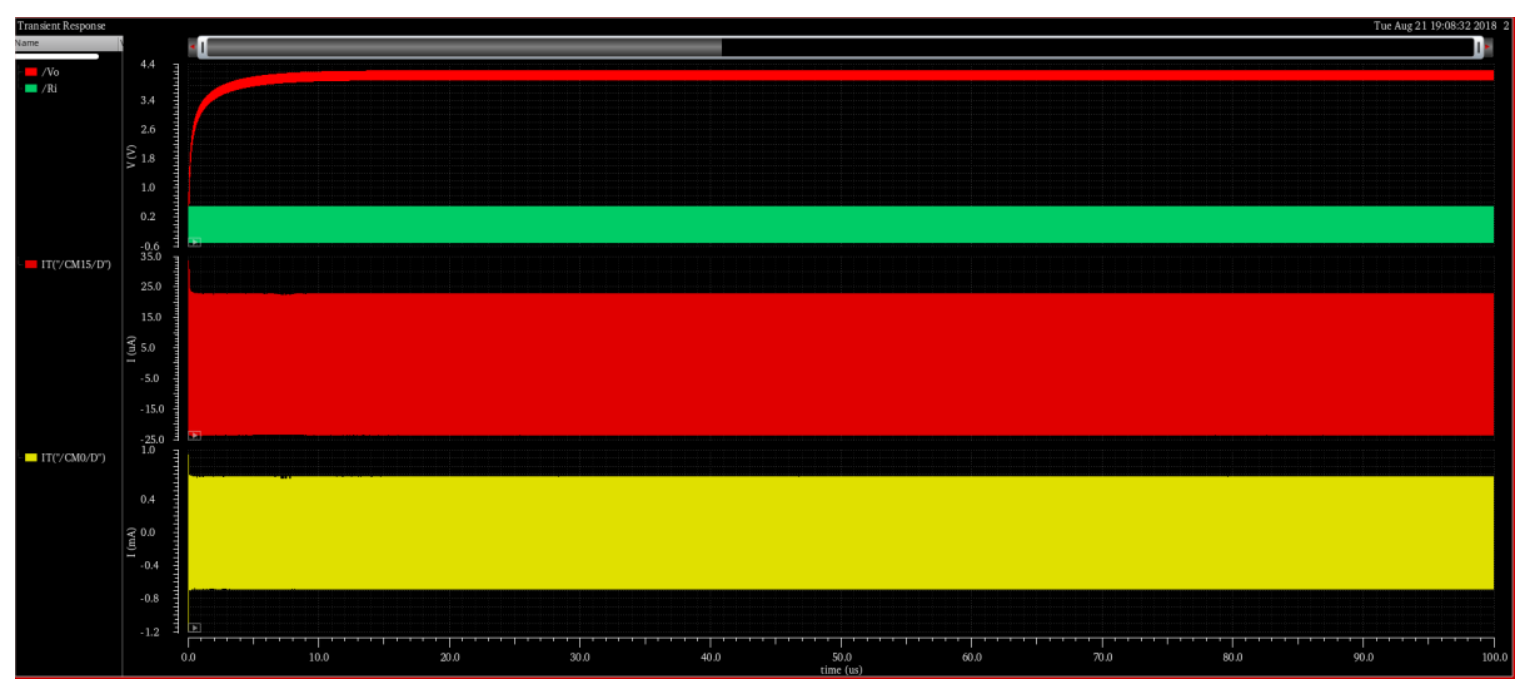

Figure 5. 9: Transient response of final design

As seen from Table 5.2, a maximum power of $96.6 \mu \mathrm{W}$ is achieved for $\mathrm{W} / \mathrm{L}$ ratio $\mathrm{R} 4$ and using a capacitance of $3.5 \mathrm{pF}$. Figure 5.9 shows the transient response of this final design. The output current is shown under IT ('CM15/D') and the input current is shown under IT ('CM0'). The input and output results from the simulation are shown in Table 5.3 below. 
Table 5. 3: Input-Output results from the simulations of amplifier

\begin{tabular}{|c|c|c|}
\hline Parameter & Input & Output \\
\hline $\mathrm{I}_{\text {peak }}$ & $676 \mu \mathrm{A}$ & $23 \mu \mathrm{A}$ \\
\hline $\mathrm{I}_{\mathrm{rms}}$ & $478 \mu \mathrm{A}$ & $16 \mu \mathrm{A}$ \\
\hline $\mathrm{V}_{\text {peak }}$ & $500 \mathrm{mV}$ & $4.2 \mathrm{~V}$ \\
\hline $\mathrm{V}_{\mathrm{rms}}$ & $353 \mathrm{mV}$ & $4.082 \mathrm{~V}$ \\
\hline $\mathrm{P}_{\max }$ & $338 \mu \mathrm{W}$ & $96.6 \mu \mathrm{W}$ \\
\hline $\mathrm{P}_{\mathrm{rms}}$ & $168 \mu \mathrm{W}$ & $93.91 \mu \mathrm{W}$ \\
\hline Efficiency(rms/peak) & \multicolumn{2}{|c|}{$55.66 \% / 28.57 \%$} \\
\hline
\end{tabular}

The final design is simulated for different input voltage levels. The results of the simulations are shown in Table 5.4. This helps us determine the least amount of input voltage required to meet the minimum requirements of output voltage. We can then determine the least amount of input power required to meet the output voltage requirements. The least amount of voltage required to achieve the minimum output voltage requirements of $4.0 \mathrm{~V}$ is $480 \mathrm{mV}$. This corresponds to an input power of $-18 \mathrm{dBm}$.

Table 5. 4: Output voltages resulting from given input voltage levels

\begin{tabular}{|l|l|}
\hline Input voltage $(\mathrm{mV})$ & Output voltage $(\mathrm{V})$ \\
\hline 300 & 2.2 \\
\hline 400 & 3.2 \\
\hline 480 & 4.0 \\
\hline 500 & 4.2 \\
\hline 600 & 5.2 \\
\hline 700 & 6.1 \\
\hline
\end{tabular}

\subsection{Layout}

What makes IC technology so promising is the size of the transistors. For the 8RF technology the channel length of the transistors can be as small as 130nm. Layout design is all about efficiently connecting all the transistors in the schematic on a physical level to minimize delays, reduce parasitics and optimize performance. We need obtain maximum 
possible current to ensure maximum power is available for storage. Figure 5.10 shows a 3D view of a NMOS transistor. The distance between the two $\mathrm{n}^{+}$doped regions is the channel length $\mathrm{L}$ of the transistors. The distance by which the gate stretches across this channel is the width $\mathrm{W}$ of the gate. As seen from equation 5.5, the ratio $\mathrm{W} / \mathrm{L}$, determines the amount of current through each transistor. Layout design is done in three ways, full custom, semi-custom and automatic. This thesis uses a semi-custom layout option. Once the layout is complete, the software can calculate all the potential parasitic resistances and capacitances in the circuit. This information can be impended with the schematic to give a better model of the circuit to be designed.

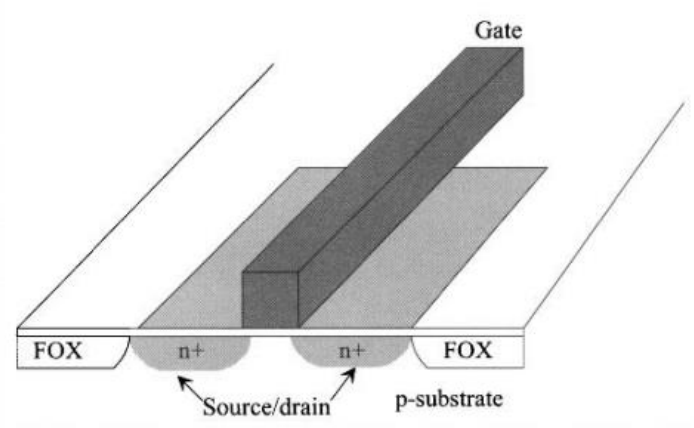

(a)

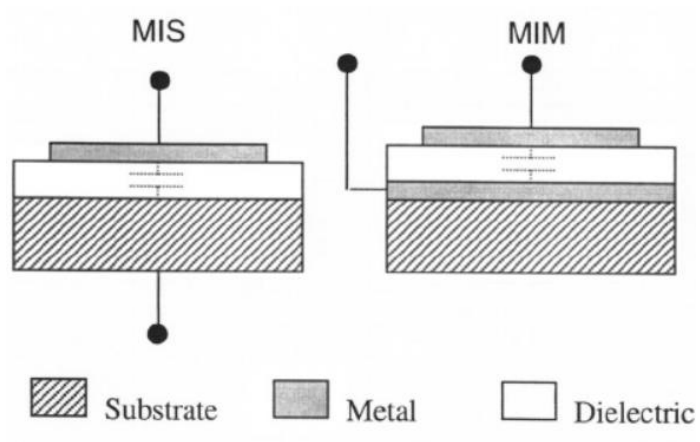

(b)

Figure 5. 10: (a) 3D view of NMOS structure (b) Structure of MIM and MIS capacitor ${ }^{[32]}$

The major components of our amplifier circuit are transistors and capacitors. Therefore, before starting with the layout process, it is important to know the process limitations imposed by the foundry and whether the design meets those requirements. As discussed previously, the minimum length offered by the process is $130 \mathrm{~nm}$. The capacitors used in this design are called MIMCAP, short for Metal Insulator Metal Capacitors. Figure 5.10 shows the structure of MIMCAP. There is a thin dielectric placed between two thin sheets of metal ${ }^{[31]}$. The figure also shows a MIS capacitor where the bottom metal plate is 
reduced by a doped substrate. The MIM aspect ratio cannot be larger than 3:1. Our design has an aspect ratio of $4: 3$, so it is well within the requirements. The capacitance per area information is given by the fabricator and the size of capacitors is calculated for the required capacitance.

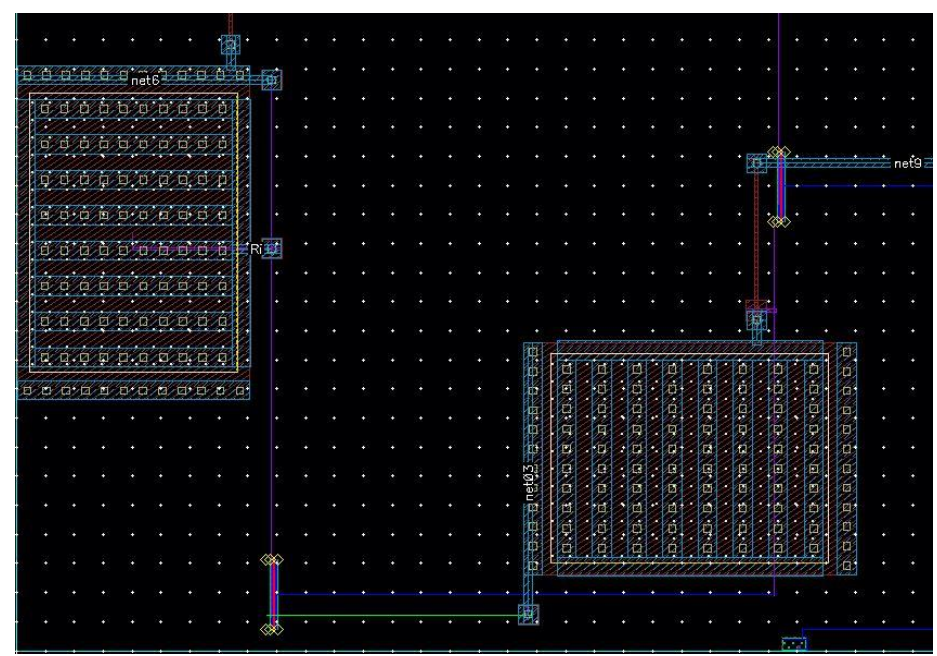

Figure 5. 11: Layout of single stage of amplifier

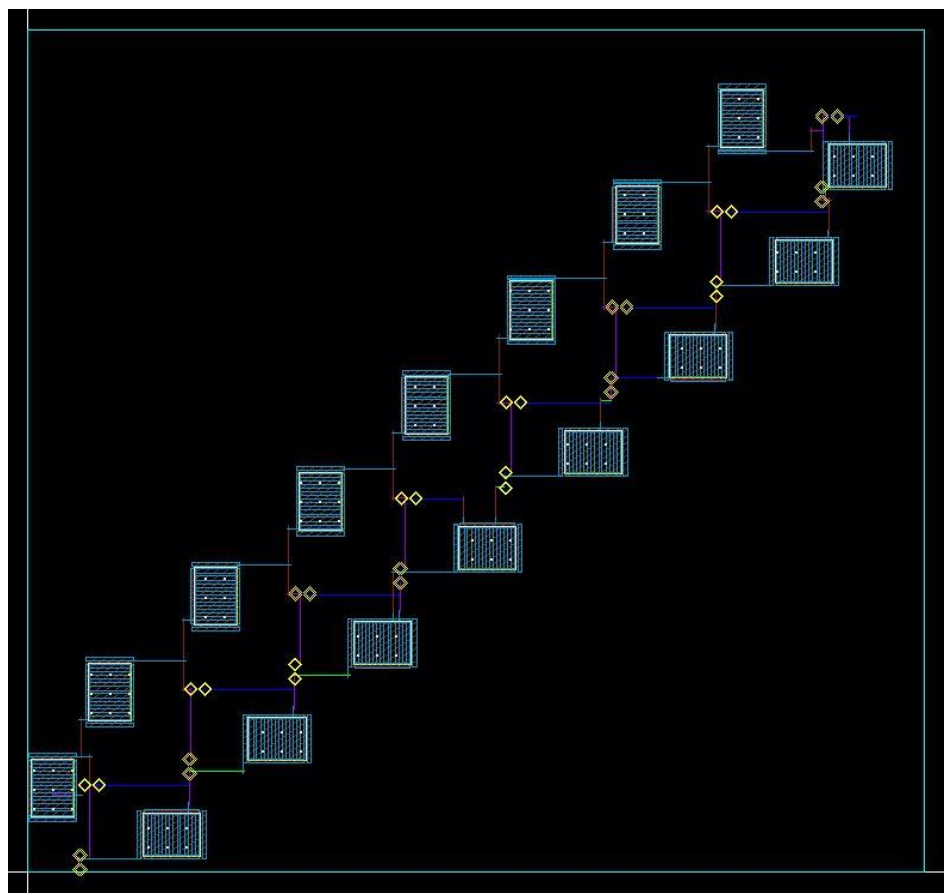

Figure 5. 12: Layout of the final eight stage amplifier 
The results of the automatic layout are shown in Figure 5.12 and Figure 5.13. The layout of a single stage of the amplifier is shown in figure 5.12. The larger structures are MIMCAPs and the two identical smaller structures are the NMOS transistors. The same pattern is repeated to realize an eight-stage amplifier shown in Figure 5.13. The components in the layout are currently placed similar to schematic. This design can be further optimized to reduce the amount of area it consumes.

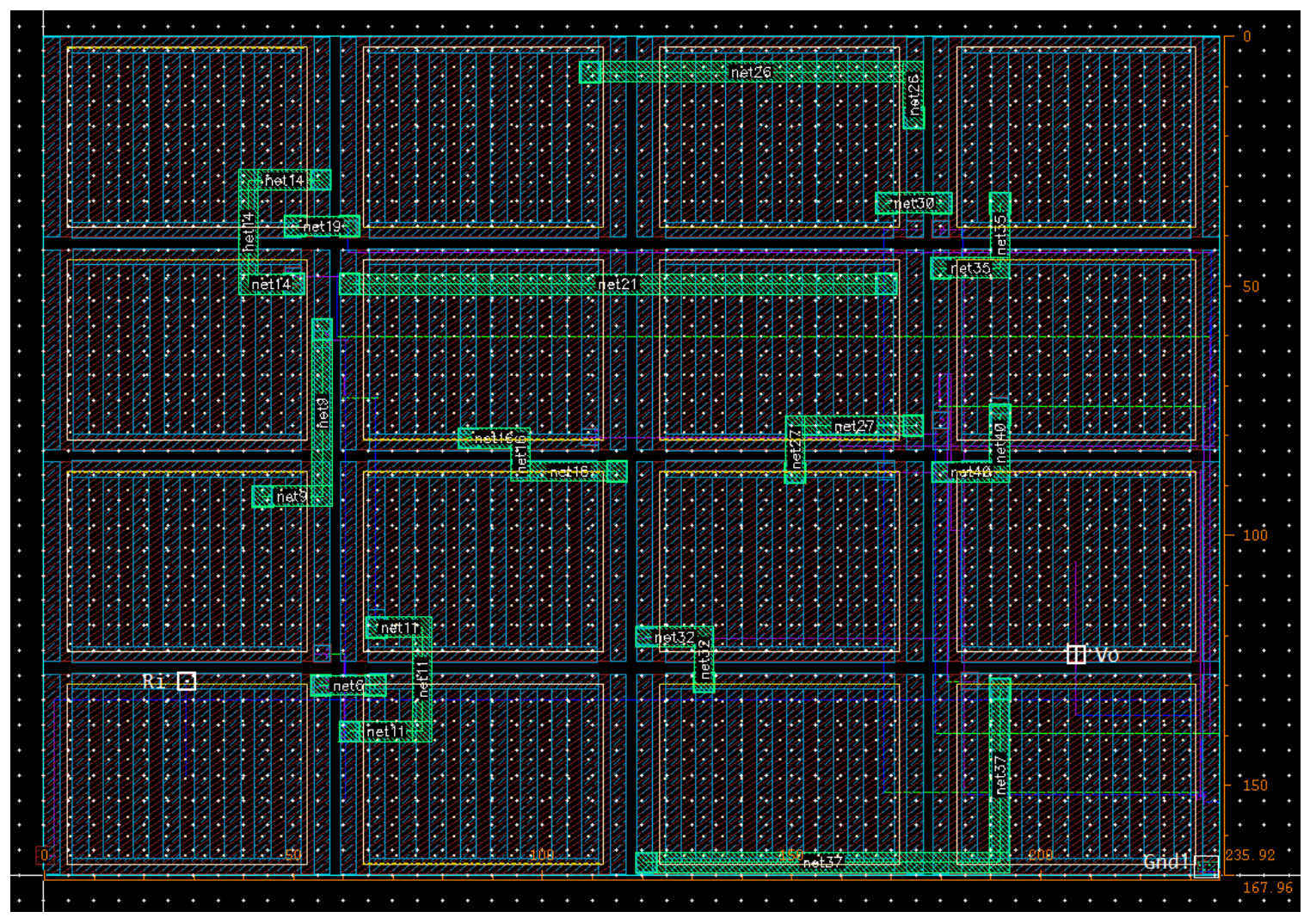

Figure 5. 13: Final optimized layout

The layout shown in Figure 5.12 occupies a square of $800 \mu \mathrm{m}$ X $800 \mu \mathrm{m}$. This area can be reduced by an optimized layout shown in Figure 5.12. The capacitors occupy major area in the circuit and hence stacking them optimally reduces the space required. The layout occupies an area of $236 \mu \mathrm{m} \mathrm{X} 168 \mu \mathrm{m}$. The input Ri is on the left and the output Vo is on the right. The ground connection is given at the bottom right corner. 


\subsection{Applications}

The harvested power can be stored in a solid-state battery as discussed in section 2.4. The output voltage of our final design is $4.2 \mathrm{~V}$ at peak and the output current is $23 \mu \mathrm{A}$ at peak. This fulfills the basic requirement to charge Enerchip CBC005 model of the battery shown in Figure 2.7. The device could also be used to charge CBC050 battery model, but due to its higher capacity, it would take longer time to charge the CBC050 compared to the CBC005 model. It should be noted however, that there is a ripple at the output voltage of the amplifier which could potentially decrease the life of the battery ${ }^{[29]}$.

The energy harvesting device can also be integrated directly with an application instead of charging a battery. However, with ambient power harvesting, the availability of power is not certain all the time. Due to that reason it would be better to have a battery backup available. Table 5.5 lists a variety of low voltage, low power requirement applications. Each circuit has its own input voltage requirement. The designed RF energy harvesting device can be integrated with the listed applications with a DC-DC converter block in between. Ikeda et. al [22] have proposed Wireless Sensor Network node that operates on $0.5 \mathrm{~V}$ and consumes $830 \mu \mathrm{W}$ at a data rate of $300 \mathrm{kbps}$. If the node is adjusted

for lower data rates, it consumes less power. Ma et. al [26] propose a medical implant that operates at $0.8 \mathrm{~V}$ and consumes only $340 \mu \mathrm{W}$ of power at $1 \mathrm{Mbps}$ data rate. 
Table 5. 5: Potential applications that can be integrated with RF energy harvesting device

\begin{tabular}{|l|l|l|l|l|l|}
\hline Description & $\begin{array}{l}\text { Voltage } \\
(\mathrm{V})\end{array}$ & $\begin{array}{l}\text { Power } \\
(\mu \mathrm{W})\end{array}$ & Speed & $\begin{array}{l}\text { Frequen } \\
\mathrm{cy}\end{array}$ & $\begin{array}{l}\text { Modulation } \\
\text { type }\end{array}$ \\
\hline $\begin{array}{l}\text { Ikeda et. al [22] TX/RX } \\
\text { Wireless Sensor Network }\end{array}$ & 0.5 & 830 & $\begin{array}{l}300 \\
\mathrm{kbps}\end{array}$ & $\begin{array}{l}5.85 \\
\mathrm{GHz}\end{array}$ & OOK \\
\hline $\begin{array}{l}\text { Thien et. al [23] RX Wireless } \\
\text { Sensor }\end{array}$ & 0.6 & 53 & $\begin{array}{l}100 \\
\mathrm{kbps}\end{array}$ & $\begin{array}{l}920 \\
\mathrm{MHz}\end{array}$ & OOK \\
\hline $\begin{array}{l}\text { Chen et al. [24] RX Wireless } \\
\text { Sensor }\end{array}$ & $1 \mathrm{~V}$ & 54 & $\begin{array}{l}200 \\
\mathrm{kbps}\end{array}$ & $\begin{array}{l}433 \\
\mathrm{MHz}\end{array}$ & OOK/FSK/PSK \\
\hline $\begin{array}{l}\text { Mercier et al. [25] TX } \\
\text { Wireless Sensor }\end{array}$ & 0.8 & $78 \mathrm{pW}$ & $1 \mathrm{~b} / \mathrm{s}$ & $2.4 \mathrm{GHz}$ & OOK/FSK \\
\hline $\begin{array}{l}\text { Ma et. al [26] TX/RX Medical } \\
\text { Implant }\end{array}$ & 0.8 & 340 & $\begin{array}{l}1 \\
\mathrm{Mbps}\end{array}$ & $\begin{array}{l}405 \\
\mathrm{MHz}\end{array}$ & OOK \\
\hline
\end{tabular}




\section{CHAPTER 6}

\section{CONCLUSION}

This thesis presents design of an RF energy harvesting device that consists of an antenna, matching circuit and an amplifier chip. Two antenna designs are proposed in this thesis, one for $915 \mathrm{MHz}$ and one for $2.4 \mathrm{GHz}$. The antenna dimensions are $100 \mathrm{~mm} \mathrm{X} 79.18$ $\mathrm{mm}$ and $38 \mathrm{~mm} \mathrm{X} 30.75 \mathrm{~mm}$ respectively. Either of the two antennas can be selected depending upon the size constraints and frequency band for energy harvesting. According to the survey of RF power in San Luis Obispo, the peak ambient power available between $2.3 \mathrm{GHz}-2.5 \mathrm{GHz}$ is between -20 to $-30 \mathrm{dBm}$, which corresponds to a range of $1 \mu \mathrm{W}-10$ $\mu \mathrm{W}$. However, the amplifier requires a minimum of $-18 \mathrm{dBm}$ to generate an output voltage high enough to charge the Enerchip battery. This would require slightly higher power than the observed power levels. The ambient power available between $800-1000 \mathrm{MHz}$ is below $-40 \mathrm{dBm}$ which is too little for the amplifier to generate the desired output. Hence given the choices, a $2.4 \mathrm{GHz}$ antenna is best suited for San Luis Obispo. If a manual transmitter is used to supply the power, then either antenna can be used. Also, if a different battery or application is used which requires input voltage less than $4 \mathrm{~V}$, the amplifier can be used at the observed power levels. The relationship between input and output voltage is given in Table 5.4. Table 6.1 provides a summary of the design. 
Table 6. 1: Summary of the designed RF energy harvesting device

\begin{tabular}{|c|c|c|c|c|}
\hline \multirow[t]{8}{*}{ Antenna } & \multirow[t]{4}{*}{$915 \mathrm{MHz}$} & \multicolumn{2}{|c|}{ Dimensions (mm) } & $100 \times 79.18$ \\
\hline & & \multicolumn{2}{|c|}{ Range of operation } & $800 \mathrm{MHz}-1000 \mathrm{MHz}$ \\
\hline & & \multicolumn{2}{|c|}{ Max/Min gain in desired region } & $5.8 \mathrm{~dB} / 5 \mathrm{~dB}$ \\
\hline & & \multicolumn{2}{|c|}{$\begin{array}{l}\text { Max/Min efficiency in desired } \\
\text { region }\end{array}$} & $90 \% / 76 \%$ \\
\hline & \multirow{4}{*}{$2.4 \mathrm{GHz}$} & \multicolumn{2}{|c|}{ Dimensions $(\mathrm{mm})$} & $38 \times 30.75$ \\
\hline & & \multicolumn{2}{|c|}{ Range of operation } & $2300-2500 \mathrm{MHz}$ \\
\hline & & \multicolumn{2}{|c|}{ Max/Min gain in desired region } & $6.3 \mathrm{~dB} / 5.2 \mathrm{~dB}$ \\
\hline & & \multicolumn{2}{|c|}{$\begin{array}{l}\text { Max/Min efficiency in desired } \\
\text { region }\end{array}$} & $99 \% / 75 \%$ \\
\hline \multirow{2}{*}{$\begin{array}{l}\text { Matching } \\
\text { circuit }\end{array}$} & \multirow{2}{*}{ LC high pass } & $915 \mathrm{MHz}$ & $\mathrm{L} / \mathrm{C}$ & $60.6 \mathrm{nF} / 498.98 \mathrm{fF}$ \\
\hline & & $2.4 \mathrm{GHz}$ & $\mathrm{L} / \mathrm{C}$ & $53.6 \mathrm{nH} / 82.2 \mathrm{fF}$ \\
\hline \multirow{5}{*}{$\begin{array}{l}\text { Amplifier } \\
\text { IC } \\
\text { (Simulation } \\
\text { results) }\end{array}$} & $\begin{array}{l}\mathrm{V}_{\text {peak }} \\
\text { (input/output) }\end{array}$ & \multicolumn{3}{|c|}{$500 \mathrm{mV} / 4.2 \mathrm{~V}$} \\
\hline & $\begin{array}{l}\mathrm{I}_{\text {peak }} \\
\text { (input/output) }\end{array}$ & \multicolumn{3}{|c|}{$676 \mu \mathrm{A} / 23 \mu \mathrm{A}$} \\
\hline & $\begin{array}{l}\mathrm{P}_{\text {peak }} \\
\text { (input/output) }\end{array}$ & \multicolumn{3}{|c|}{$338 \mu \mathrm{W} / 96.6 \mu \mathrm{W}$} \\
\hline & Efficiency & \multicolumn{3}{|l|}{$28.57 \%$} \\
\hline & Area & \multicolumn{3}{|c|}{$236 \mu \mathrm{m} X 168 \mu \mathrm{m}$} \\
\hline
\end{tabular}




\section{CHAPTER 7}

\section{FUTURE WORK}

\subsection{Voltage regulator}

The output of the amplifier shows a ripple of similar frequency as the input frequency. This fluctuation in voltage is undesired by many applications. It can also make it difficult to charge the battery properly. A DC-DC voltage converter or a rectifier circuit can help stabilize the output of the device and make it more reliable. A different topology for the amplifier circuit can be tried as well. Salter et al. ${ }^{[38]}$ use a switch capacitor DC-DC converter as their amplifier circuit. This provides a DC voltage across load.

\subsection{Verification of design}

The design of the amplifier circuit has been simulated successfully. However, the circuit was simulated without any information regarding the parasitic capacitances and resistances. The layout of the design can be used to generate an extracted view of the schematic with all parasitic information. ADS and Cadence have a link that can be used to test the antenna, matching circuit and the amplifier circuit all together. The entire system needs to be simulated before fabrication. The antenna needs to be tested in an anechoic chamber to experimentally determine the antenna gain vs frequency. The next step would be to get the chip fabricated and test it under various input conditions. The total input impedance can be experimentally determined, and the matching circuit can be changed accordingly. This would give a better transfer of input power from antenna to amplifier circuit. 


\subsection{Smaller antenna}

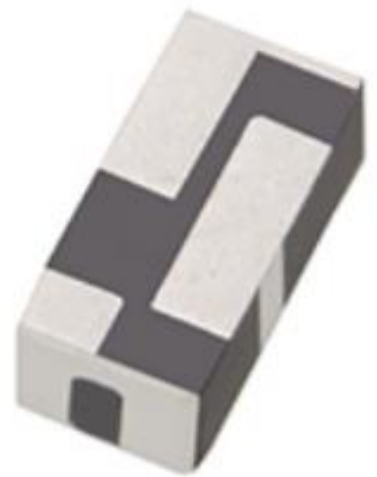

(a)

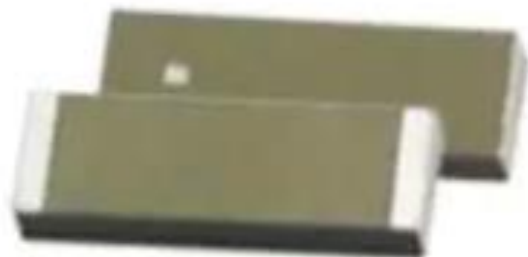

(b)

Figure 7. 1: (a) Molex multi band ceramic chip antenna ${ }^{[36]}$ (b) Abracon $915 \mathrm{MHz}$ ceramic chip antenna ${ }^{[37]}$

There are some applications which have strict size constraints. The area of the fabricated chip is $1.5 \mathrm{~mm} \times 1.5 \mathrm{~mm}$ based on the pad rings available for design. The size of the battery CBC005 is $1.7 \mathrm{~mm} X 2.25 \mathrm{~mm}$. Compared to this the antenna size is much larger. A smaller antenna can be designed to further scale down the total size of the device. There are various commercially available small antennas that can be used with the device. Figure 7.1 shows two ceramic chip antennas. Molex antenna has a length of $3.2 \mathrm{~mm}$ and Abracon antenna has a length of $12 \mathrm{~mm}$. This brings down the overall size of the device. 


\section{REFERENCES}

[1] T. Itoh, "Ultra low power wireless sensor nodes for expanding application of the Internet of Things," 2016 IEEE CPMT Symposium Japan (ICSJ), Kyoto, 2016, pp. 74-75. doi: 10.1109/ICSJ.2016.7801319

[2] Y. Liang, X. Meng, Y. Hu and K. Zhang, "Design and implementation of an ultralow power wireless sensor network for indoor environment monitoring," 2017 IEEE 17th International Conference on Communication Technology (ICCT), Chengdu, 2017, pp. 937-940. doi: 10.1109/ICCT.2017.8359772

[3] Zhihua Wang, Xiaoyu Zhang, Xinkai Chen, Lingwei Zhang and Hanjun Jiang, "An energy-efficient ASIC with real-time work-on-demand for wireless body sensor network," 2008 IEEE International Conference on Electron Devices and SolidState Circuits, Hong Kong, 2008, pp. 1-6. doi: 10.1109/EDSSC.2008.4760681

[4] Texas Instruments, 'The Evolution of Internet of Things", White Paper, 2013.

[5] Minh-Thien Hoang, Nobuyuki Sugii, Koichiro Ishibashi, "A 1.36 $\mu \mathrm{W} 312-315 \mathrm{MHz}$ synchronized-OOK receiver for wireless sensor networks using $65 \mathrm{~nm}$ SOTB CMOS technology" Solid-State Electronics, Volume 117, 2016, pp. 161-169. doi: 10.1016/ISSN 0038-1101

[6] Federal Communications Commission, "FCC Table of Frequency Allocation" .Available: $\underline{\text { https://transition.fcc.gov/oet/spectrum/table/fcctable.pdf }}$

[7] Balanis, Constantine A. Antenna Theory, Analysis and Design. Third ed. Hoboken, NJ: John Wiley \& Sons, 2005. 
[8] A. S. Andrenko, Xianyang Lin and Miaowang Zeng, "Outdoor RF spectral survey: A roadmap for ambient RF energy harvesting," TENCON 2015 - 2015 IEEE Region 10 Conference, Macao, 2015, pp. 1-4. doi: 10.1109/TENCON.2015.7373140

[9] J. C. Kwan and A. O. Fapojuwo, "Measurement and Analysis of Available Ambient Radio Frequency Energy for Wireless Energy Harvesting," 2016 IEEE 84th Vehicular Technology Conference (VTC-Fall), Montreal, QC, 2016, pp. 1-6. doi: 10.1109/VTCFall.2016.7881084

[10] T. Beng Lim, N. M. Lee and B. K. Poh, "Feasibility study on ambient RF energy harvesting for wireless sensor network," 2013 IEEE MTT-S International Microwave Workshop Series on RF and Wireless Technologies for Biomedical and Healthcare Applications (IMWS-BIO), Singapore, 2013, pp. 1-3. doi: 10.1109/IMWS-BIO.2013.6756226

[11] X. Lu, P. Wang, D. Niyato, D. I. Kim and Z. Han, "Wireless Networks With RF Energy Harvesting: A Contemporary Survey," in IEEE Communications Surveys \& Tutorials, vol. 17, no. 2, pp. 757-789, Secondquarter 2015. doi: 10.1109/COMST.2014.2368999

[12] Powercast, "TX91501 - 915 MHz Powercaster TM Transmitter". Available: http://www.powercastco.com/products/powercaster-transmitter/

[13] FCC code of regulations 47CFR Part 15. Available: https://www.law.cornell.edu/cfr/text/47/part-15

[14] J. W. Zhang et al., "Wireless energy harvesting using serially connected voltage doublers," 2010 Asia-Pacific Microwave Conference, Yokohama, 2010, pp. 41-44. 
[15] P. Nintanavongsa, U. Muncuk, D. R. Lewis and K. R. Chowdhury, "Design Optimization and Implementation for RF Energy Harvesting Circuits," in IEEE Journal on Emerging and Selected Topics in Circuits and Systems, vol. 2, no. 1, pp. 24-33, March 2012. doi: 10.1109/JETCAS.2012.2187106

[16] D. Karolak, T. Taris, Y. Deval, J. Béguéret and A. Mariano, "Design comparison of low-power rectifiers dedicated to RF energy harvesting," 2012 19th IEEE International Conference on Electronics, Circuits, and Systems (ICECS 2012), Seville, 2012, pp. 524-527. doi: 10.1109/ICECS.2012.6463693

[17] FCC, "Cellular Market Areas Map". Available: https://www.fcc.gov/sites/default/files/wireless/auctions/data/maps/CMA.pdf

[18] FCC, "Chart of Licenses". Available: https://wireless2.fcc.gov/UlsEntry/attachments/attachmentViewRD.jsp?applType $=$ search\&fileKey=1382746707\&attachmentKey=18830422\&attachmentInd=appl $\underline{\text { Attach }}$

[19] Cellular communication transmission towers in San Luis Obispo, CA. Available: http://www.cellreception.com/towers/towers.php?city=SAN+LUIS+OBISPO\&sta $\underline{\text { te } \_ \text {abr }=c a}$

[20] N. Abdullah, A. M. Shire, E. Mohd and A. M. Shire, "Rectenna for RF energy harvesting," 2016 International Conference on Advances in Electrical, Electronic and Systems Engineering (ICAEES), Putrajaya, 2016, pp. 318-321. doi: 10.1109/ICAEES.2016.7888061

[21] Rogers et al. Radio Frequency Integrated Circuit Design. First ed. Norwood, MA: Artech House, Inc. 2003. 
[22] S. Ikeda et al., "A 0.5-V 5.8-GHz low-power asymmetrical QPSK/OOK transceiver for wireless sensor network," The 20th Asia and South Pacific Design Automation Conference, Chiba, 2015, pp. 40-41. doi: 10.1109/ASPDAC.2015.7058976

[23] H. M. Thien, N. Sugii and K. Ishibashi, "A $53 \mu \mathrm{W}-82 \mathrm{dBm}$ sensitivity $920 \mathrm{MHz}$ OOK receiver design using bias switch technique on 65nm SOTB CMOS technology," 2014 SOI-3D-Subthreshold Microelectronics Technology Unified Conference (S3S), Millbrae, CA, 2014, pp. 1-2. doi: 10.1109/S3S.2014.7028185

[24] S. Chen and K. Cheng, "A 433 MHz $54 \mu \mathrm{W}$ OOK/FSK/PSK compatible wake-up receiver with $11 \mu \mathrm{W}$ low-power mode based on injection-locked oscillator," ESSCIRC Conference 2016: 42nd European Solid-State Circuits Conference, Lausanne, 2016, pp. 137-140. doi: 10.1109/ESSCIRC.2016.7598261

[25] P. P. Mercier, S. Bandyopadhyay, A. C. Lysaght, K. M. Stankovic and A. P. Chandrakasan, "A $78 \mathrm{pW} 1 \mathrm{~b} / \mathrm{s} 2.4 \mathrm{GHz}$ radio transmitter for near-zero-power sensing applications," 2013 Proceedings of the ESSCIRC (ESSCIRC), Bucharest, 2013, pp. 133-136. doi: 10.1109/ESSCIRC.2013.6649090

[26] C. Ma, C. Hu, J. Cheng, L. Xia and P. Y. Chiang, "A Near-Threshold, 0.16 nJ/b OOK-Transmitter With 0.18 nJ/b Noise-Cancelling Super-Regenerative Receiver for the Medical Implant Communications Service," in IEEE Transactions on Biomedical Circuits and Systems, vol. 7, no. 6, pp. 841-850, Dec. 2013. doi: 10.1109/TBCAS.2013.2253555

[27] Neamen Donald A. Solid State Electronics. Fourth ed. New York, NY: McGraw Hill, 2012. 
[28] D. Al-Shebanee, R. Wunderlich and S. Heinen, "Design of highly sensitive CMOS RF energy harvester using ultra-low power charge pump," 2015 IEEE Wireless Power Transfer Conference (WPTC), Boulder, CO, 2015, pp. 1-4. doi: 10.1109/WPT.2015.7140163

[29] Cymbet Corporation, "Enerchip Bare Die Rechargeable Solid-State Batteries Datasheet". Available: http://www.cymbet.com/pdfs/DS-72-41\%20v6.pdf

[30] T. Le, K. Mayaram and T. Fiez, "Efficient Far-Field Radio Frequency Energy Harvesting for Passively Powered Sensor Networks," in IEEE Journal of SolidState Circuits, vol. 43, no. 5, pp. 1287-1302, May 2008. doi: 10.1109/JSSC.2008.920318

[31] B. Landgraf, "Capacitors in heterogeneous IC systems-Consequences on compact modeling," 2014 Proceedings of the 21st International Conference Mixed Design of Integrated Circuits and Systems (MIXDES), Lublin, 2014, pp. 62-65. doi: 10.1109/MIXDES.2014.6872154

[32] Baker Jacob R. CMOS circuit design, layout, and simulation. Third ed. Piscataway, NJ: IEEE press, 2010.

[33] ITO, "Radio Spectrum Management in China". Available: https://www.itu.int/en/ITU-D/RegionalPresence/AsiaPacific/Documents/Events/2017/Sep-SECB/Presentations/D1-2Kan\%20RuntianRadio\%20Spectrum\%20Management\%20Strategies\%20in\%20China.pdf 
[34] Singapore Spectrum Allocation Chart. Available: https://www.imda.gov.sg/$\underline{\text { Imedia/imda/files/regulation-licensing-and-consultations/frameworks-and- }}$ policies/spectrum-management-and-coordination/spectrumchart.pdf?la=en

[35] Radio Spectrum Allocations, Canada. Available: https://www.ic.gc.ca/eic/site/smtgst.nsf/vwapj/spectallocation-08.pdf/\$FILE/spectallocation-08.pdf

[36] Molex, "Ceramic Chip Antenna Datasheet" Available: https://www.mouser.com/datasheet/2/276/2030070001_ANTENNAS1218567.pdf

[37] Abracon, "Ceramic Chip Antenna Datasheet" Available: https://www.mouser.com/datasheet/2/3/ACAG1204-915-T-1314113.pdf

[38] T. Salter, K. Choi, M. Peckerar, G. Metze and N. Goldsman, "RF energy scavenging system utilising switched capacitor DC-DC converter," in Electronics Letters, vol. 45, no. 7, pp. 374-376, 26 March 2009. doi: 10.1049/el.2009.0153 